\title{
Avaliação da Toxicidade nas Sementes de Pimentão "Capsicum Annum L.", Caracterização Físico-Química e Microbiológica em Amostras de Esgoto Doméstico de Recife-PE
}

\section{Evaluation of Toxicity in Pepper Seeds "Capsicum Annum L.", Physical-Chemical and Microbiological Characterization in Domestic Sewage Samples of Recife-PE}

\author{
Niraldo M.M. Melo ${ }^{1}$, Cristiane M. Moraes ${ }^{2}$, Dinaldo C. Oliveira², Fernando F.S. Dias ${ }^{3}$, Carolina \\ G.C. Oliveira ${ }^{4}$, Mohand Benachour ${ }^{2}$, Yana B. Brandão ${ }^{1 *}$
}

\begin{abstract}
RESUMO
A presente pesquisa tem como objetivo avaliar, a partir de uma análise físico-química, microbiológica e testes de fitotoxicidade, as amostras de esgoto domésticos coletadas em alguns edifícios da Região Metropolitana do Recife-PE, após o tratamento desses efluentes em Reator UASB (Upflow Anaerobic Sludge Blanket), a fim de avaliar sua a eficiência de tratamento. Os testes de fitotoxicidade foram realizados nas sementes de Pimentão "Capsicum Annum L." nesses efluentes, a partir de um planejamento fatorial $\left(2^{2}\right)$ com dois níveis e dois fatores. Assim, nas referidas amostras foram realizadas as análises de DQO (Demanda Química de Oxigênio), DBO (Demanda Biológica de Oxigênio), T (Temperatura), OG (Óleos e Graxas), pH (potencial Hidrogeniônico), SD60 (Sólidos Sedimentáveis), Coliformes: Totais e Termotolerantes. Os resultados mostraram estar de acordo com a legislação do CONAMA (Conselho Nacional de Meio Ambiente) no tratamento de esgoto com o reator UASB. A toxicidade das amostras na saída do reator UASB tiveram 83,33\% de IG (Índice de Germinação)< $80 \%$ e 16,67\% de IG entre 80$120 \%$, o que indica a presença de substâncias que estimulam a germinação das sementes de pimentão.
\end{abstract}

Palavras-chave: Análise Físico-Química; Análise Microbiológica; Toxicidade; Capsicum Annum L.

\section{ABSTRACT}

This research aims to evaluate, from a physicochemical, microbiological analysis and phytotoxicity tests, the domestic sewage samples collected in some buildings of the Metropolitan Region of Recife-PE, after the treatment of these effluents in UASB Reactor (Upflow Anaerobic Sudgel Blanket), in order to evaluate its treatment efficiency. Phytotoxicity tests were performed on the pepper seeds "Capsicum Annum L." in these effluents, based on a factorial planning $\left(2^{2}\right)$ with two levels and two factors. Thus, in these samples were analyzed of COD (Chemical Oxygen Demand), BOD (Biological Oxygen Demand), $\mathrm{T}$ (Temperature), OG (Oils and Greases), pH (Hydrogenionic potential), SD60 (Sedimentable Solids), Coliforms: Total and Thermotolerant. The results showed that they were in accordance with the legislation of CONAMA (National Council on the Environment) in the treatment of sewage with the UASB reactor. The toxicity of the samples at the exit of the UASB reactor had $83.33 \%$ of IG (Germination Index) $<80 \%$ and $16.67 \%$ of GI between $80-120 \%$, which indicates the presence of substances that stimulate the germination of the chili seeds.

Keywords: Physical-Chemical Analysis; Microbiological Analysis; Toxicity; Capsicum Annum L.

\footnotetext{
${ }^{1}$ Universidade Federal Rural de Pernambuco (UFRPE), UACSA, Cabo de Santo Agostinho, PE; ${ }^{2}$ Universidade Federal de Pernambuco (UFPE), Recife-PE; ${ }^{3}$ Universidade do Agreste de Pernambuco (UFAPE)/UFRPE, Garanhuns-PE; ${ }^{4}$ Centro Universitário Maurício de Nassau (UNINASSAU), Recife-PE. *E-mail: yanabatista@yahoo.com.br; yana.brandao@ufrpe.br
} 


\section{INTRODUÇÃO}

A Lei de Saneamento Básico (SB) n ${ }^{0} 11.445$ de 2007 foi um Marco regulatório, que estabeleceu as normas para um Plano Nacional de Saneamento Básico (Plansab) (BRASIL, 2013), que visa a definição para a elaboração de um planejamento ambiental e as suas diretrizes. Dentre os principais fatores para atender às exigências estabelecidas no Plansab estão o abastecimento de água, o esgotamento sanitário, o manejo de resíduos sólidos e a drenagem de águas pluviais urbanas. Assim, o SB tem sido compreendido como uma fiscalização dos parâmetros físicos. A forma inadequada de empregar esse sanemaneto em uma região, tende à acarretar em sérios riscos para a vida humana, que necessita de toda essa infraestrutura do sistema de SB para viver com saúde, evitando assim, incidências de doenças e mortes, destruição do ecossistema, extresse emocional, dentre outros. Esses fatores ocorrem principalmente nos países em desenvolvimento e menos favorecidos em sua economia (REIS et al., 2017; CARCARÁ et al., 2019).

Atualmente, o Brasil encontra-se em uma condição suscetível, devido ao desprovimento de um planejamento adequado, no que se refere ao saneamento básico, de acordo com o SNIS (Sistema Nacional de Informações sobre Saneamento) de 2017, onde os dados apresentados mostraram que apenas $73,7 \%$ do esgoto obtido têm sido tratado e descartado de forma adequada. Esse fator apresentado relata a importância de elaborar um planejamento ambiental, a fim de aumentar o tratamento desses esgotos, que são simplesmente descartados em fossas sépticas ou através das correntes d'água. Diante desse aspecto, a escassez por um esgoto limpo e tratado acarreta em sérios riscos tanto ao meio ambiente, quanto na saúde da população, que utimamente têm exigido melhorias e soluções desses problemas apresentados, no que se refere ao cumprimento das legislações ambientais estabelecidas pelos membros do poder público. A pressão da opinião por parte da população mostrou para os governantes de vários países a importância de estabelecer leis ambientais, que delimitassem as faixas de concentrações dos poluentes em esgotos rejeitados ao meio ambiente. Assim, dados reportados na literatura têm apresentado as demandas para a definição de estratégias, a fim de melhorar os processos já existentes e desenvolver tecnologias limpas (LEONET et al., 2011; PEREIRA et al., 2021).

As substâncias químicas tóxicas presentes nos esgotos constantemente contaminam os fluxos d'água quando descartadas de forma inadequada. A toxicidade desses compostos no meio ambiente aquático tem tido bastante importância, devido aos seus níveis de concentração em mg. $L^{-1}$, poder apresentar riscos ambientais com consequências nefastas para a flora e a fauna. Assim, os diversos compostos químicos presentes nesses esgotos devem ser identificados e monitorados constantemente, evitando novas contaminações ao meio ambiente (BRANDÃO et al., 2011; SIEBERT et al., 2020; MELO et al., 2021). 
Segundo projeção feita pelo IBGE (Instituto Brasileiro de Geografia e Estatística), baseada em estudo realizado em 2021, a população brasileira ultrapassou a faixa dos 213 milhões de habitantes, onde $85 \%$ habitam os centros urbanos e $15 \%$ vivem em zonas rurais. E, por conta desse aumento, os centros urbanos atualmente não possuem infraestrutura adequada para fornecer condições ideais para os habitantes. Essas regiões precisam ser bem planejadas, a fim de obter as soluções necessárias e eficazes na coleta e tratamento adequado do esgoto domestico, de acordo com os requisidos estabelecidos pelas legislações ambientais para a caracterização das amostras, após análises físico-químicas e microbiológicas (SIEBERT et al., 2020).

A importância de um saneamento básico em uma região reflete na saúde pública, tendo em vista que, uma gestão planejada do meio ambiente possibilita a prevenção de doenças diversas infecciosas para toda uma população, tais como, COVID-19, febre tifoide, cólera, disenterias, hepatite infecciosa, diversos tipos de verminoses (BORTH et al., 2017). Algumas pesquisas tem demostrado recentemente que o mecanismo fecal-oral é uma forma também de se contaminar por difusão da doença, tais como, COVID-19, além de aerossóis e gotículas respiratórias (GU; HAN; WANG, 2020; GWENZI, 2020). Alguns fatores de profilaxia também devem ser levados em consideração para evitar os riscos de adquirir essas doenças, como exemplo, o cuidado básico na higienização das mãos com água limpa e sabão. Os mais jovens costumam ser as pessoas mais afetadas por essas doenças, aonde muitas vezes chegam a óbito (CARUSO; FREEMAN, 2020; MUSHI; SHAO, 2020; WHO, 2020).

Neste aspecto, a melhoria para que um saneamento ambiental seja implementado em uma determinada lozalização é bastante relevante para a inserção de um processo, que estabeleça o tratamento de esgoto ou uma destinação correta desses resíduos gerados. Assim, o tratamento físico-químico e biológico vem sendo constantemente empregado, sendo uma forma de tratamento necessária na maioria das vezes desses efluentes, antes de serem descartados nos fluxos d'água e sem acarretar riscos para o meio ambiente e a saúde da população (FERRI, 2014). Os efluentes líquidos muitas vezes podem apresentar substâncias tóxicas difíceis de degradarem, devido à composição característica de cada poluente (MELO et al., 2021). Sendo assim, existe a necessidade da utilização de outros métodos mais eficazes e processos mais avançados, tais como, os Processos Oxidativos Avançados (POAs). Essa tecnologia é bastante relevante para oxidar esses compostos orgânicos, onde costumam empregar os radicais hidroxila $(\bullet \mathrm{OH})$, a fim de destruir por oxidação essas cargas tóxicas presentes nesses efluentes (BRANDÃO et al., 2010; MERT et al., 2010; KIM; IHM, 2011; BRANDÃO et al., 2013; ZHANG et al., 2016; BRANDÃO et al., 2017; MATAFONOVA; BATOEV, 2018; AFZAL et al., 2019; BRANDÃO et al., 2021).

Devido às condições adequadas de clima, o tratamento anaeróbio de efluentes foi difundido pelo Brasil, e esse tipo de tratamento possui diversas vantagens em relação à baixa produção de 
sólidos, custo benefício, simplicidade operacional e baixo consumo de energia, por não necessitar de sopradores (CHERNICHARO, 2016). Dentre os diversos sistemas que utilizam o processo anaeróbio para o tratamento de esgoto, o reator de fluxo ascendente UASB (Upflow Anaerobic Sludge Blanket, em inglês) é um dos sistemas mais utilizados, quando se tem limitação de área para implantação (RIBEIRO, 2016). Além disso, apresenta satisfatória remoção de DBO (Demanda Biológica de Oxigênio) e de DQO (Demanda Química de Oxigênio) (DBO/DQO) (65-75\%).

A avaliação da toxicidade nas sementes de Pimentão "Capsicum annum l.", por exemplo, mostra a composição desses esgotos com as substâncias químicas presentes, sendo um método capaz de complementar as análises químicas através desses ensaios de ecotoxicidade e analisar a qualidade do efluente contaminante. Essas análises pela técnica do bioindicador representam os níveis de poluentes existentes que chegam a danificar e prejudicar o meio ambiente (SANTOS et al., 2017; MICHELAN et al., 2021). O teste de bioensaio com as sementes de pimentão, por exemplo, mostra claramente à importância da eficiência de analisar a fitotoxicidade do efluente, devido as carasterísticas que a semente apresenta, pois o tegumento e o endosperma do bioindicador possibilita a ação de organismos tóxicos encontrados nos esgotos, devido a resistência à germinação no meio ambiente em que se encontram presentes (BISOGNIN et al., 2005; LI et al., 2005).

O objetivo deste trabalho foi investigar efluentes de esgoto doméstico de determinados condomínios da Região Metropolitana do Recife-PE, em um período de 1 ano através de análises físico-químicas e microbiológicas. Essas amostras foram coletadas em 4 diferentes condomínios, na entrada e na saída de cada diferente estação de esgoto e em triplicata de cada ponto. O tratamento do esgoto doméstico foi realizado em reatores anaeróbios tipo UASB. Na caracterização físico-química das referidas amostras foram avaliados os seguintes parâmetros: Temperatura, potencial Hidrogeniônico (pH), Óleos e Graxas (OG), Sólidos Decantáveis (SD60), DQO (Demanda Química de Oxigênio), DBO (Demanda Biológica de Oxigênio). Na determinação das análises microbiológicas foram investigados os seguintes fatores: Coliformes Totais e Coliformes Termotolerantes. A importância na determinação dessas análises se torna relevante para comprovar com a obtenção dos parâmeteos físico-químicos e microbiológicos, que os resultados apresentados são viáveis e aceitáveis, estando de acordo com o cumprimento exigido pelas normas da legislação ambiental brasileira, antes desses resíduos ser descartados no meio ambiente. Outra determinação relevante também analisada nesta pesquisa foi o ensaio de ecotoxicidade nas sementes de Pimentão “Capsicum annum l." testados nesses efluentes, a partir da elaboração de um planejamento fatorial experimental completo $\left(2^{2}\right)$ com dois níveis e dois fatores. 


\section{MATERIAL E METÓDOS}

\section{Área em Estudo}

A área analisada nesta pesquisa compreende a Região Metropolitana do Recife (RMR). Neste estudo, as amostras foram coletadas nos municípios de Recife (SILVA, 2017) nos bairros de Candeias e Piedade. Assim como também, em porto de Galinhas, Ipojuca (BITOUN, 2015; REYNALDO et al., 2013). A Figura 1 mostra a localização dos 4 pontos (AM1; AM2; AM3 e AM4) das amostras coletadas nos condomínios para as referidas análises.

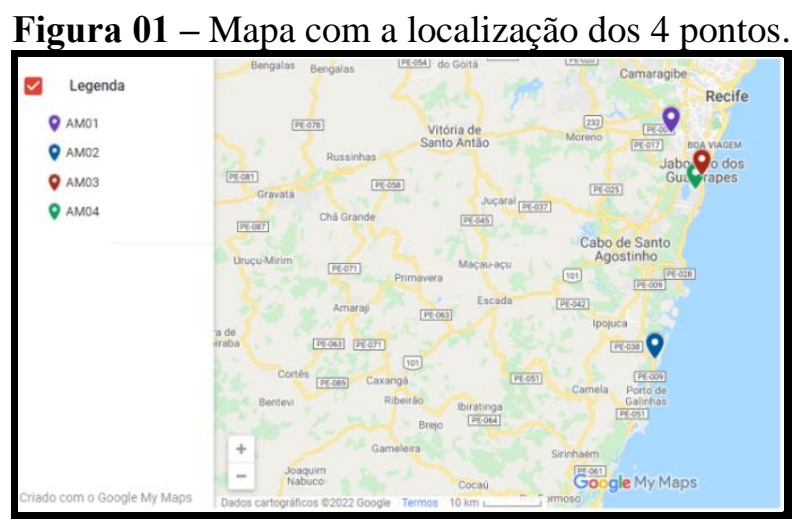

Fonte: o Autor, 2022.

\section{Desenvolvimento Experimental}

Nas amostras de esgoto doméstico coletadas foram realizados os procedimentos de análise experimental no Laboratório do Departamento de Engenharia Química (DEQ) da Universidade Federal de Pernambuco (UFPE) e também no Laboratório de Química do Departamento de Engenharia da Universidade Federal Rural de Pernambuco-Unidade Acadêmica do Cabo de Santo Agostinho (UFRPE - UACSA).

As análises das amostras realizadas em laboratório permitiu obter resultados quantitativos, a fim de considerer o cumprimento das normas ambientais vigentes para a pesquisa. Nestas amostras de esgoto doméstico foi identificada a presença de substâncias orgânicas.

Os experimentos referentes às amostras coletadas e analisadas em laboratório foram elaborados na terceira semana de cada mês, desde Agosto/2020 até Julho/2021, com as especificações adequadas de acordo com o órgão licenciador do empreendimento. A partir da coleta das amostras, em 4 pontos diferentes dentro da Região Metropolitana do Recife (RMR) foi analisado a eficiência do tratamento de esgoto doméstico em reatores anaeróbios tipo UASB (Upflow Anaerobic Sludge Blanket) utilizado nas ETA’s (Estação de Tratamento de Águas) brasileiras (BOHN et al., 2008; GASSIE; ENGLEHARDT, 2017; LI et al., 2018; MICHAELKORDATOU et al., 2018; DING et al. 2019; SCHIJVEN et al., 2019; ALCARAZ-IBARRA et al., 2020). 
Os valores encontrados nos resultados mostram a conformidade dos parâmetros estabelecidos, de acordo com o plano de monitoramento de controle operacional. As amostras coletadas nos referidos pontos foram analizadas em laboratório para a caracterização físicoquímica e microbiológica dessas amostras, de acordo com a literatura (APHA, 2005). As condições apresentadas de alguns parâmetros da Resolução 430\%/2011 do Conselho Nacional de Meio Ambiente (CONAMA) também foram seguidos e comparados com os resultados obtidos nesta pesquisa. As amostras foram coletadas na captação do efluente bruto, na entrada e na saída do reator UASB (entrada do filtro aeróbio) e no efluente tratado (após a desinfecção).

\section{Métodos Analíticos}

\section{Análises Físico-Químicas}

Os testes nos efluentes de esgoto doméstico foram analisados em triplicata para cada ponto coletado, sendo as seguintes análises físico-químicas: Temperatura $\left({ }^{0} \mathrm{C}\right)$; Demanda Química de Oxigênio (DQO) (mg. $\mathrm{O}_{2} / \mathrm{L}$ ); Demanda Bioquímica de Oxigênio (DBO) (mg.O $/ 2$ L); Óleos e Graxas-OG (mg.O $\left.\mathrm{O}_{2} / \mathrm{L}\right)$; potencial Hidrogeniônico $(\mathrm{pH})$; Sólidos Decantáveis 60 min-SD60 $(\mathrm{mL} / \mathrm{L})$. Assim como, o teste de ecotoxicidade nas sementes de Pimentão "Capsicum annum l.".

A temperatura de cada amostra foi realizada a partir da medição com um termômetro digital no local indicado de tratamento do reator UASB, na captação do efluente bruto (entrada) e no efluente tratado (saída), após a desinfecção.

O efluente de esgoto coletados em cada ponto apresentou uma característica com bastante sólidos sedimentáveis, por isso a necessidade no ensaio de ser bem misturado antes da realização das medidas de volume. Nessas amostras, seguiram-se os critérios estabelecidos para as análises de DQO, de acordo com APHA (1995). Nos tubos (hach) utilizados nos testes foram adicionados: 2,5 mL da amostra; $1,5 \mathrm{~mL}$ da solução de digestão de DQO $\left(\mathrm{K}_{2} \mathrm{Cr}_{2} \mathrm{O}_{7}\right)$ de concentração indicada para a faixa de DQO analisada; $3,5 \mathrm{~mL}$ da solução catalisada de $\mathrm{H}_{2} \mathrm{SO}_{4}$; em seguida, foram aquecidos no digestor por 2 horas e realizado a leitura no espectrofotômetro. O comprimento de onda $(\lambda)$ UV-visível para a faixa analítica de DQO esta representado a seguir: $0-40 \mathrm{mg} / \mathrm{L}(\lambda=350 \mathrm{~nm}) ; 0-150 \mathrm{mg} / \mathrm{L}(\lambda=420 \mathrm{~nm}) ; 0-1500 \mathrm{mg} / \mathrm{L}(\lambda=620 \mathrm{~nm})$. Os testes nas concentrações entre $0-40$ e $0-1500 \mathrm{mg} / \mathrm{L}$ foram analisados as leituras em (\%) de transmitância, e na concentração de 0-1500 mg/L, essas resultados apresentados estão de acordo com a sua Absorbância. Assim, a curva analítica determinada para a DQO foi obtida de acordo com os resultados da absorbância apresentados no espectrofotômetro. Logo, todos os 4 testes analisados em triplicada de cada ponto, mostraram um comprimento de onda de $620 \mathrm{~nm}$. Uma amostra em água destilada foi também utilizada para representar o branco nas análises. A Eq. (1) mostra a determinação da DQO (MELO et al., 2021). 


$$
D Q O\left(\frac{m g}{L}\right)=a \cdot x+b
$$

Onde: $a=$ Constante da curva analítica de DQO (coeficiente angular da reta de ajuste); $b=$ Constante da curva analítica de DQO (coeficiente linear da reta de ajuste); $x=$ Absorbância obtida no espectrofotômetro $(\lambda=620 \mathrm{~nm})$.

Na determinação da DQO foi obtida uma solução padrão, e em seguida foi realizada as medidas dessa solução, a fim de identificar a curva de calibração. As concentrações das soluções padrões foram realizadas para cada específica faixa analítica, após as suas diluições para a obtenção dos valores de DQO. A solução padrão foi o hidrogenoftalato de potássio (KHP).

De acordo com a concentração da DQO nas referidas amostras, as massas de KHP foram secas em estufa a $103^{\circ} \mathrm{C}$ por 2 horas, e em seguida, aferidas em balão volumétrico de $100 \mathrm{~mL}$ nas seguintes concentrações: 0 à $40 \mathrm{mg} / \mathrm{L}(0,0043 \mathrm{~g}), 0$ à $150 \mathrm{mg} / \mathrm{L}(0,0128 \mathrm{~g})$ e 0 à $1500 \mathrm{mg} / \mathrm{L}$ $(0,1280 \mathrm{~g})$. Após essa etapa, a solução de cada amostra foi transferida para um frasco de vidro com tampa e mantido sobre refrigeração por até 3 meses (MELO et al., 2021).

Nos testes realizados para análise de $\mathrm{DBO}$, as amostras foram adquiridas em frascos de vidro pyrex e resfriadas a $4^{\circ} \mathrm{C}$ durante $24 \mathrm{~h}$ (APHA, 1995). O volume utilizado foi $1000 \mathrm{~mL}$. As amostras foram diluídas de acordo com a concentração ideal obtida. Os frascos de DBO foram identificados com as amostras incubadas a $20^{\circ} \mathrm{C}$ sem interferência da luz, durante 5 dias, sendo assim, também foram identificados à concentração de OD (Oxigênio Dissolvido) a paritr do método de Winkler modificação azida (APHA, 1995). As Eqs. (2) e (3) mostram a determinação da $\mathrm{DBO}$ em $20^{\circ} \mathrm{C}$ durante 5 dias.

$$
\mathrm{DBO}\left(\mathrm{mg} . \mathrm{O}_{2} / \mathrm{L}\right)=\frac{T_{1}-T_{5}}{C \%} \times \mathrm{f}_{\mathrm{s}} \times 100 \%
$$

ou

$$
\mathrm{DBO}\left(\mathrm{mg} \cdot \mathrm{O}_{2} / \mathrm{L}\right)=\frac{O D_{1}-O D_{5}}{C \%} \times 100 \%
$$

Onde: $\mathrm{T}_{1}=$ volume gasto de tiossulfato de sódio no primeiro dia; $\mathrm{T}_{5}=$ volume gasto de tiossulfato de sódio no quinto dia; $\mathrm{C} \%=$ Concentração ideal; fs= fator de correção da solução de tiossulfato de sódio $0,025 \mathrm{~N} ; \mathrm{OD}_{1}=$ Oxigênio dissolvido no primeiro dia; $\mathrm{OD}_{5}=$ Oxigênio dissolvido no quinto dia.

A quantidade de compostos que podem estar presentes em uma amostra, e que não são volatilizados durante a sua extração com um solvente em evaporação a $100^{\circ} \mathrm{C}$, pode ser determinado, como Óleos e Graxas (OG). Na análise de OG determinado nesta pesquisa, foi 
utilizado 1L da amostra de esgoto doméstigo. A amostra foi bem homogeneizada e logo em seguida, transferida para um funil de decantação para acrescentar $40 \mathrm{~mL}$ de hexano e esperar a separação das fases presentes. Assim, o hexano foi então destilado e adicionado em estufa durante 1 hora para ser reciclado.

Os Sólidos Decantáveis (SD)60 se torna uma análise importante dentre as séries de sólidos, para a elaboração e montagem da infraestrutura de unidades de sedimentação, no tratamento de sistema de esgotos, mostrando a sua eficiência (BATALHA, 1977; BASSETT, 1981; APHA, 1995; MS, 2000). Nesta pesquisa foi utilizado 1L de efluente real de esgoto doméstico para a realização desta análise. A amostra foi homogeneizada e transferida para o cone Imhoff, decantada durante 45 min e com um bastão de vidro foi raspada suavemente as paredes do cone decantando por mais $15 \mathrm{~min}$. Após $60 \mathrm{~min}$, foi realizada a leitura do volume de material sedimentado, em mL/L de resíduo (APHA, 1975; NIRALDO et al., 2021).

A análise do potencial Hidrogeniônico $(\mathrm{pH})$ em uma amostra de esgoto doméstico é sempre importante e necessária, principalmente para identificar futuros problemas na infraestrutura de sistema de tratamento, devido a possíveis corrosão nas instalações hidráulicas e no sistema de distribuição. Assim como também, o pH da amostra necessita ser sempre determinado, devido a influência na coagulação química e na desinfecção desses efluentes (MS, 2000). O pH das amostras foi medido a partir do equipamento $\mathrm{pH}$-metro de bancada, marca Phtek Phs-3b Labtec de precisão Digital (MELO et al., 2021).

\section{$\underline{\text { Análises Microbiológicas }}$}

Nesta etapa, a técnica de Colilert-18 foi utilizada e quantificada nas amostras de efluentes, a fim de determinar nos ensaios microbiológicos, os Coliformes Totais (NMP/100 mL) e os Coliformes Termotolerantes (Escherichia Coli-E.C.) (NMP/100 mL).

As amostras foram irradiadas em uma caixa de medição, contendo em seu interior uma lâmpada UV-A de comprimento de onda igual $365 \mathrm{~nm}$ e uma potência de $6 \mathrm{~W}$. Assim, foram utilizados frascos estéreis graduados com capacidade para $100 \mathrm{~mL}$, flaconetes com meio de cultura, cartelas estéreis com 97 cavidades fornecendo a contagem de 1 até 2.419 por cada amostra de $100 \mathrm{~mL}$ sem diluições. O processo foi desenvolvido dentro da capela de fluxo laminar, sendo cada amostra diluída sequencialmente. Após seladas, as cartelas foram incubadas por 24 horas a $35^{\circ} \mathrm{C} \pm 0,5^{\circ} \mathrm{C}$ em estufa bacteriológica. Na referida cartela, a cor incolor representa que não há presença de coliformes totais e Escherichia Coli, a cor amarela mostra a presença de coliformes totais e a cor amarela/fluorescente significa que existe a presença de Escherichia Coli (SIERBERT et al., 2020; MELO et al., 2021). 


\section{$\underline{\text { Teste de Toxicidade }}$}

Os testes de ecotoxicidade nas sementes de Pimentão "Capsicum annum l." testados nesses efluentes de esgoto doméstico real foi realizado a partir da elaboração de um planejamento fatorial experimental completo $\left(2^{3}\right)$ com dois níveis e três fatores. A norma 850 da Agência de Proteção Ambiental dos Estados Unidos (USEPA) foi estabelecida nestas análises, seguindo os seus parâmetros (USEPA, 1996). O controle positivo foi realizado com uma solução de Sulfato de zinco $\left(\mathrm{ZnSO}_{4}\right)$, enquanto o controle negativo foi obtido com água destilada.

As Tabelas 1 e 2 apresentam o planejamento experimental $2^{2}$, com as variáveis de entrada (Concentração da Amostra (CA)-\% e pH) e as variáveis de saída (Comprimento médio da Raiz (CR)-mm, Índices de Crescimento Radicular (ICR) e Índices de Germinação (IG)-\%) das amostras, respectivamente.

As amostras utilizadas nas Tabelas 1 e 2 foram diluídas com água destilada e em seguida utilizado o planejamento fatorial experimental completo $\left(2^{2}\right)$ com dois níveis e dois fatores, nos seguintes parâmetros: nas concentrações das amostras- 33,33\%; 66,66\% e 99,99\%; e, nas concentrações de pH-3,25; 6,50 e 9,75.

A variação dos valores de pH de 3,25; 6,50 e 9,75 foram obtidas em meio ácido e básico, respectivamente, a partir das soluções de ácido fosfórico $\left(\mathrm{H}_{3} \mathrm{PO}_{4}\right)$ e hidróxido de sódio $(\mathrm{NaOH})$.

As sementes de Pimentão "Capsicum annum l." foram posicionadas em cada placa de petri, em torno de 10 sementes, e em seguida, acrescentados em cada placa 2,5 $\mathrm{mL}$ da solução solubilizada no $\mathrm{pH}$ definido no ensaio. Assim, as placas foram seladas com filme de PVC e colocadas em incubadora, em uma temperature de $20^{\circ} \mathrm{C}$ durante 6 dias.

As amostras contidas nas placas de petri estiveram na incubadora de acordo com alternância de luminosidade, para a disposição do crescimento natural da semente. Após 6 dias, as sementes da Capsicum annum l. foram avaliadas em seu índice de germinação, dando importância a $5 \mathrm{~mm}$ para o tamanho padrão de sua radícula.

O Índice de Crescimento Radicular (ICR) e o Índice de Germinação (IG) foram quantificados, utilizando as seguintes Eq. (4) e (5).

\section{Índice de Crescimento Radicular}

$$
I C R=\frac{C R A}{C R C}
$$

Onde: $I C R=$ Índice de crescimento radicular; $C R A=$ Comprimento da radícula na amostra; $C R C=$ Comprimento da radícula no controle (negativo). 


\section{Índice de Germinação}

$$
I G=I C R \times\left(\frac{S G A}{S G C}\right) \times 100
$$

Onde: $I G=$ Índice de germinação; $I C R=$ Índice de crescimento radicular; $S G A=$ Número de sementes germinadas na amostra; $S G C=$ Número de sementes germinadas no controle (negativo).

Tabela 1: Ensaios de fitotoxicidade (Entrada) - Agosto 2020/Julho 2021.

\begin{tabular}{|c|c|c|c|c|c|}
\hline Amostra & $\begin{array}{c}\text { Concentração da } \\
\text { amostra (\%) }\end{array}$ & pH & $\begin{array}{l}\text { Comprimento } \\
\text { médio da raiz } \\
(\mathrm{mm})\end{array}$ & ICR & $I G(\%)$ \\
\hline Branco & 0 & - & 5,0 & 1 & 100 \\
\hline AM1 & 33,33 & 3,25 & - & - & - \\
\hline AM2 & 33,33 & 3,25 & 0,0 & 0,0 & 0,0 \\
\hline AM3 & 33,33 & 3,25 & 3,0 & 0,6 & 7,5 \\
\hline AM4 & 33,33 & 3,25 & 0,0 & 0,0 & 0,0 \\
\hline AM1 & 66,66 & 3,25 & - & - & - \\
\hline AM2 & 66,66 & 3,25 & 2,5 & 0,5 & 37,5 \\
\hline AM3 & 66,66 & 3,25 & 1,5 & 0,3 & 33,75 \\
\hline AM4 & 66,66 & 3,25 & 0,0 & 0,0 & 0,0 \\
\hline AM1 & 99,99 & 3,25 & 4,0 & 0,8 & 60,0 \\
\hline AM2 & 99,99 & 3,25 & 5,0 & 1,0 & 25,0 \\
\hline AM3 & 99,99 & 3,25 & 2,2 & 0,44 & 44,0 \\
\hline AM4 & 99,99 & 3,25 & 1,6 & 0,32 & 20,0 \\
\hline AM1 & 33,33 & 6,50 & - & - & - \\
\hline AM2 & 33,33 & 6,50 & 0,0 & 0,0 & 0,0 \\
\hline AM3 & 33,33 & 6,50 & 1,3 & 0,26 & 19,5 \\
\hline AM4 & 33,33 & 6,50 & 2,2 & 0,44 & 55,0 \\
\hline AM1 & 66,66 & 6,50 & - & - & - \\
\hline AM2 & 66,66 & 6,50 & 1,6 & 0,32 & 28,0 \\
\hline AM3 & 66,66 & 6,50 & 3,0 & 0,6 & 60 \\
\hline AM4 & 66,66 & 6,50 & 0,0 & 0,0 & 0,0 \\
\hline AM1 & 99,99 & 6,50 & 6,0 & 1,2 & 90,0 \\
\hline AM2 & 99,99 & 6,50 & 4,0 & 0,8 & 10,0 \\
\hline AM3 & 99,99 & 6,50 & 2,5 & 0,5 & 37,5 \\
\hline AM4 & 99,99 & 6,50 & 2,5 & 0,5 & 37,5 \\
\hline AM1 & 33,33 & 9,75 & - & - & - \\
\hline AM2 & 33,33 & 9,75 & 0,0 & 0,0 & 0,0 \\
\hline AM3 & 33,33 & 9,75 & 0,0 & 0,0 & 0,0 \\
\hline AM4 & 33,33 & 9,75 & 2,0 & 0,4 & 25,0 \\
\hline AM1 & 66,66 & 9,75 & - & - & - \\
\hline AM2 & 66,66 & 9,75 & 0,0 & 0,0 & 0,0 \\
\hline AM3 & 66,66 & 9,75 & 2,63 & 0,526 & 39,45 \\
\hline AM4 & 66,66 & 9,75 & 0,0 & 0,0 & 0,0 \\
\hline AM1 & 99,99 & 9,75 & 7,8 & 1,56 & 97,5 \\
\hline AM2 & 99,99 & 9,75 & 0,0 & 0,0 & 0,0 \\
\hline AM3 & 99,99 & 9,75 & 2,8 & 0,56 & 70,0 \\
\hline AM4 & 99,99 & 9,75 & 0,0 & 0,0 & 0,0 \\
\hline
\end{tabular}

AM: Amostra 
Tabela 2: Ensaios de fitotoxicidade (Saída) - Agosto 2020/Julho 2021.

\begin{tabular}{|c|c|c|c|c|c|}
\hline Amostra & $\begin{array}{l}\text { Concentração da } \\
\text { amostra }(\%)\end{array}$ & pH & $\begin{array}{c}\text { Comprimento } \\
\text { médio da raiz } \\
(\mathrm{mm})\end{array}$ & ICR & $I G(\%)$ \\
\hline Branco & 0 & - & 5,0 & 1 & 100 \\
\hline AM1 & 33,33 & 3,25 & 3,0 & 0,6 & 15,0 \\
\hline AM2 & 33,33 & 3,25 & 4,0 & 0,8 & 80,0 \\
\hline AM3 & 33,33 & 3,25 & 0,0 & 0,0 & 0,0 \\
\hline AM4 & 33,33 & 3,25 & 0,0 & 0,0 & 0,0 \\
\hline AM1 & 66,66 & 3,25 & 2,6 & 0,52 & 19,5 \\
\hline AM2 & 66,66 & 3,25 & 4,2 & 0,84 & 94,5 \\
\hline AM3 & 66,66 & 3,25 & 0,0 & 0,0 & 0,0 \\
\hline AM4 & 66,66 & 3,25 & 2,3 & 0,46 & 17,25 \\
\hline AM1 & 99,99 & 3,25 & 1,2 & 0,24 & 12,0 \\
\hline AM2 & 99,99 & 3,25 & 4,66 & 0,932 & 104,85 \\
\hline AM3 & 99,99 & 3,25 & 0,0 & 0,0 & 0,0 \\
\hline AM4 & 99,99 & 3,25 & 1,3 & 0,26 & 9,75 \\
\hline AM1 & 33,33 & 6,50 & 0,0 & 0,0 & 0,0 \\
\hline AM2 & 33,33 & 6,50 & 2,75 & 0,55 & 48,12 \\
\hline AM3 & 33,33 & 6,50 & 0,0 & 0,0 & 0,0 \\
\hline AM4 & 33,33 & 6,50 & 0,0 & 0,0 & 0,0 \\
\hline AM1 & 66,66 & 6,50 & 2,0 & 0,4 & 25,0 \\
\hline AM2 & 66,66 & 6,50 & 4,3 & 0,86 & 75,25 \\
\hline AM3 & 66,66 & 6,50 & 5,0 & 1,0 & 25,0 \\
\hline AM4 & 66,66 & 6,50 & 1,0 & 0,2 & 7,5 \\
\hline AM1 & 99,99 & 6,50 & 1,0 & 0,2 & 7,5 \\
\hline AM2 & 99,99 & 6,50 & 5,625 & 1,125 & 98,43 \\
\hline AM3 & 99,99 & 6,50 & 3,5 & 0,7 & 17,5 \\
\hline AM4 & 99,99 & 6,50 & 0,0 & 0,0 & 0,0 \\
\hline AM1 & 33,33 & 9,75 & 4,0 & 0,8 & 20,0 \\
\hline AM2 & 33,33 & 9,75 & 2,0 & 0,4 & 50,0 \\
\hline AM3 & 33,33 & 9,75 & 1,1 & 0,22 & 16,5 \\
\hline AM4 & 33,33 & 9,75 & 1,7 & 0,34 & 17,0 \\
\hline AM1 & 66,66 & 9,75 & 0,0 & 0,0 & 0,0 \\
\hline AM2 & 66,66 & 9,75 & 4,5 & 0,9 & 90,0 \\
\hline AM3 & 66,66 & 9,75 & 2,1 & 0,42 & 26,25 \\
\hline AM4 & 66,66 & 9,75 & 0,0 & 0,0 & 0,0 \\
\hline AM1 & 99,99 & 9,75 & 3,0 & 0,6 & 30,0 \\
\hline AM2 & 99,99 & 9,75 & 4,0 & 0,8 & 80,0 \\
\hline AM3 & 99,99 & 9,75 & 3,1 & 0,62 & 46,5 \\
\hline AM4 & 99,99 & 9,75 & 0,0 & 0,0 & 0,0 \\
\hline
\end{tabular}

AM: Amostra

\section{RESULTADOS E DISCUSSÃO}

\section{Análises Físico-Químicas e Microbiológicas}

As Tabelas 3, 4, 5 e 6 apresentam os valores dos ensaios físico-químicos e microbiológicos das amostras (AM1, AM2, AM3 e AM4), que foram obtidos em cada estação de coleta de tratamento, na entrada e na saída. As Figuras 2, 3, 4 e 5 mostram mais claramente a interpretação desses resultados para as análises: $\mathrm{T}\left({ }^{0} \mathrm{C}\right)(-\mathrm{e}-\mathrm{s}) ; \mathrm{pH}(-) \quad(-\mathrm{e}-\mathrm{s}) ; \mathrm{OG}(\mathrm{mg} / \mathrm{L})(-\mathrm{e}-\mathrm{s})$; $\mathrm{SD} 60(\mathrm{~mL} / \mathrm{L})(-\mathrm{s}) ; \quad \mathrm{DQO}\left(\mathrm{mgO}_{2} / \mathrm{L}\right)(-\mathrm{e}-\mathrm{s}) ; \quad \mathrm{DBO}\left(\mathrm{mgO}_{2} / \mathrm{L}\right)(-\mathrm{e}-\mathrm{s}) ; \quad \mathrm{CT}(\mathrm{NMP} / 100 \mathrm{~mL})(-\mathrm{s}) \quad$ e $\mathrm{EC}(\mathrm{NMP} / 100 \mathrm{~mL})(-\mathrm{s})$, onde -e e $-\mathrm{s}$ representam, respectivamente, a entrada e a saída. Assim, essas análises mostram como esta a qualidade do efluente descartado no meio ambiente, e que estão dentro das normas vigentes e estabelecidas na Resolução 430\%/2011 do CONAMA, após um tratamento em reator UASB. 
Tabela 3: Resultados das Análises Físico-químicas e Microbiológicas para AM1.

\begin{tabular}{|c|c|c|c|c|c|c|c|c|c|c|c|c|}
\hline AM1 & & & 2020 & & & & & & 21 & & & \\
\hline - & Ago & Set & Out & Nov & Dez & Jan & Fev & Mar & Abr & Mai & Jun & Jul \\
\hline T-e & 28,7 & 28,9 & 29,0 & 29,3 & 29,0 & 29,4 & 29,3 & 29,3 & 29,2 & 29,5 & 29,4 & 29,3 \\
\hline T-s & 29,3 & 29,5 & 29,4 & 29,6 & 29,5 & 29,8 & 29,7 & 29,8 & 29,6 & 29,8 & 29,6 & 29,7 \\
\hline DQO-e & 62,4 & 57,6 & 33,2 & 37,6 & 35,3 & 30,3 & 49,5 & 62,5 & 33,7 & 47,5 & 30,0 & 157,5 \\
\hline DQO-s & 15,4 & 34,2 & 27,5 & 24,3 & 25,2 & 23,3 & 21,6 & 15,0 & 25,4 & 23,8 & 22,7 & 33,8 \\
\hline DBO-e & 13,7 & 12,2 & 4,3 & 5,1 & 4,5 & 7,4 & 8,6 & 14,3 & 3,0 & 8,0 & 7,2 & 31,8 \\
\hline DBO-s & 3,8 & 4,1 & 2,4 & 3,3 & 2,5 & 3,5 & 3,1 & 2,5 & 2,7 & 4,0 & 3,5 & 4,0 \\
\hline OG-e & 13,4 & 17,3 & 14,2 & 15,7 & 14,4 & 14,1 & 19,3 & 11,0 & 31,9 & 16,6 & 10,3 & 17,5 \\
\hline OG-s & 8,1 & 9,0 & 4,7 & 3,3 & 4,2 & 3,1 & 7,6 & 7,2 & 5,7 & 3,2 & 1,8 & 9,3 \\
\hline pH-e & 6,8 & 6,3 & 6,5 & 6,4 & 6,6 & 6,6 & 6,7 & 6,7 & 6,1 & 6,7 & 6,2 & 6,5 \\
\hline pH-s & 6,3 & 6,0 & 6,1 & 6,0 & 6,1 & 6,2 & 6,1 & 7,0 & 6,3 & 5,6 & 5,6 & 5,8 \\
\hline SD60-e & - & - & - & - & - & - & - & - & - & - & - & - \\
\hline SD60-s & 0,8 & 0,1 & 0,7 & 0,5 & 0,2 & 0,4 & 0,4 & 0,1 & 0,3 & 0,4 & 0,2 & 0,1 \\
\hline CT-e & - & - & - & - & - & - & - & - & - & - & - & - \\
\hline CT-s & $\begin{array}{c}4,7 \\
\times 10^{2}\end{array}$ & $\begin{array}{l}37,0 \\
\times 10^{3}\end{array}$ & $\begin{array}{l}19,6 \\
\times 10^{5}\end{array}$ & $\begin{array}{l}34,4 \\
\times 10^{2}\end{array}$ & $\begin{array}{l}15,7 \\
\times 10^{2}\end{array}$ & $\begin{array}{l}37,6 \\
\times 10^{3}\end{array}$ & $\begin{array}{l}30,4 \\
\times 10^{4}\end{array}$ & $\begin{array}{l}33,4 \\
\times 10^{2}\end{array}$ & 0 & $\begin{array}{l}172,6 \\
\times 10^{2}\end{array}$ & 0 & $\begin{array}{l}20,3 \\
\times 10^{3}\end{array}$ \\
\hline EC-e & - & - & - & - & - & - & - & - & - & - & - & - \\
\hline EC-s & $\begin{array}{c}2,3 \\
\times 10^{3}\end{array}$ & $\begin{array}{c}3 \\
\times 10^{2}\end{array}$ & $\begin{array}{c}5,7 \\
\times 10^{2}\end{array}$ & 0 & $\begin{array}{c}7,8 \\
\times 10^{2}\end{array}$ & $\begin{array}{c}8,8 \\
\times 10^{2}\end{array}$ & $\begin{array}{c}7,5 \\
\times 10^{2}\end{array}$ & $\begin{array}{c}6,3 \\
\times 10^{2}\end{array}$ & 0 & $\begin{array}{c}9,7 \\
\times 10^{2}\end{array}$ & 0 & $\begin{array}{l}3,81 \\
\times 10^{2}\end{array}$ \\
\hline
\end{tabular}

T $\left({ }^{0} \mathrm{C}\right)(-\mathrm{e}-\mathrm{s}) ; \mathrm{pH}(-\mathrm{e}-\mathrm{s}) ; \mathrm{OG}(\mathrm{mg} / \mathrm{L})(-\mathrm{e}-\mathrm{s}) ; \mathrm{SD} 60$ (mL/L) (-e-s); DQO $\left(\mathrm{mgO}_{2} / \mathrm{L}\right)(-\mathrm{e}-\mathrm{s})$;

$\mathrm{DBO}\left(\mathrm{mgO}_{2} / \mathrm{L}\right)(-\mathrm{e}-\mathrm{s}) ; \mathrm{CT}(\mathrm{NMP} / 100 \mathrm{~mL})(-\mathrm{e}-\mathrm{s})$ e EC $(-\mathrm{e}-\mathrm{s})(\mathrm{NMP} / 100 \mathrm{~mL})$.

-e (entrada); -s (saída)

Tabela 4: Resultados das Análises Físico-químicas e Microbiológicas para AM2.

\begin{tabular}{lllllllllllll}
\hline AM2 & & & $\mathbf{2 0 2 0}$ & & & & & \multicolumn{2}{c}{$\mathbf{2 0 2 1}$} & & \\
\hline & Ago & Set & Out & Nov & Dez & Jan & Fev & Mar & Abr & Mai & Jun & Jul \\
\hline T-e & 29,7 & 29,6 & 29,6 & 29,8 & 29,9 & 29,7 & 29,8 & 29,9 & 29,7 & 29,6 & 29,7 & 29,7 \\
T-s & 29,8 & 29,8 & 29,7 & 30,0 & 30,0 & 29,6 & 29,8 & 30,0 & 29,9 & 29,8 & 29,8 & 29,9 \\
DQO-e & 303,0 & 343,8 & 575,6 & 407,0 & 393,4 & 332,5 & 583,3 & 302,5 & 512,5 & 431,3 & 371,3 & 357,3 \\
DQO-s & 50,5 & 66,3 & 21,3 & 53,1 & 29,3 & 28,8 & 25,0 & 17,5 & 23,8 & 55,0 & 58,3 & 23,7 \\
DBO-e & 183,1 & 175,3 & 130,4 & 75,7 & 83,3 & 89,7 & 176,8 & 101,9 & 181,2 & 72,6 & 85,6 & 80,3 \\
DBO-s & 13,7 & 63,7 & 23,3 & 15,7 & 17,2 & 5,3 & 79,5 & 4,1 & 8,1 & 11,1 & 13,2 & 7,3 \\
OG-e & 22,3 & 10,1 & 9,5 & 88,8 & 71,9 & 3,9 & 10,1 & 27,6 & 33,8 & 21,1 & 30,3 & 36,0 \\
OG-s & 4,3 & 6,2 & 5,7 & 11,7 & 6,3 & 2,1 & 6,5 & 11,4 & 7,8 & 3,9 & 13,4 & 14,3 \\
pH-e & 6,7 & 6,8 & 6,9 & 7,0 & 7,1 & 6,8 & 6,5 & 6,9 & 7,5 & 7,0 & 7,2 & 6,9 \\
pH-s & 6,4 & 5,9 & 6,6 & 6,5 & 6,6 & 6,4 & 6,2 & 5,7 & 6,7 & 6,1 & 7,0 & 6,7 \\
SD60-e & - & - & - & - & - & - & - & - & - & - & - & - \\
SD60-s & 0,1 & 0,1 & 0,2 & 0,4 & 0,4 & 0,3 & 0,2 & 0,3 & 0,3 & 0,4 & 0,1 & 0,2 \\
CT-e & - & - & - & - & - & - & - & - & - & - & - & - \\
CT-s & 3,0 & 29,80 & 173,30 & 34,4 & 15,5 & 19,86 & 33,8 & 22,8 & 43,5 & 0 & 3,7 & 7,6 \\
& $\mathrm{x} 10^{5}$ & $\mathrm{x} 10^{5}$ & $\mathrm{x} 10^{5}$ & $\mathrm{x} 10^{3}$ & $\mathrm{x} 10^{3}$ & $\mathrm{x} 10^{4}$ & $\mathrm{x} 10^{2}$ & $\mathrm{x} 10^{2}$ & $\mathrm{x} 10^{3}$ & 0 & $\mathrm{x} 10^{4}$ & $\mathrm{x} 10^{4}$ \\
EC-e & - & - & - & - & - & - & - & - & - & - & - & - \\
EC-s & 2,3 & 3,0 & 5,7 & & 7,81 & 8,8 & 7,5 & 4,1 & 3,4 & & 1,5 & 2,6 \\
& $\mathrm{x} 10^{3}$ & $\mathrm{x} 10^{2}$ & $\mathrm{x} 10^{2}$ & 0 & $\mathrm{x} 10^{2}$ & $\mathrm{x} 10^{2}$ & $\mathrm{x} 10^{2}$ & $\mathrm{x} 10^{2}$ & $\mathrm{x} 10^{3}$ & 0 & $\mathrm{x} 10^{4}$ & $\mathrm{x} 10^{3}$ \\
\hline
\end{tabular}

$\mathrm{T}\left({ }^{0} \mathrm{C}\right)(-\mathrm{e}-\mathrm{s}) ; \mathrm{pH}(-\mathrm{e}-\mathrm{s}) ; \mathrm{OG}(\mathrm{mg} / \mathrm{L})(-\mathrm{e}-\mathrm{s}) ; \mathrm{SD} 60$ (mL/L) (-e-s); DQO $\left(\mathrm{mgO}_{2} / \mathrm{L}\right)(-\mathrm{e}-\mathrm{s}) ;$ $\mathrm{DBO}\left(\mathrm{mgO}_{2} / \mathrm{L}\right)(-\mathrm{e}-\mathrm{s}) ; \mathrm{CT}(\mathrm{NMP} / 100 \mathrm{~mL})(-\mathrm{e}-\mathrm{s})$ e EC $(-\mathrm{e}-\mathrm{s})(\mathrm{NMP} / 100 \mathrm{~mL})$. 
Tabela 5: Resultados das Análises Físico-químicas e Microbiológicas para AM3.

\begin{tabular}{lcccccccccccc}
\hline AM3 & & & $\mathbf{2 0 2 0}$ & & & & & & $\mathbf{2 0 2 1}$ & & \\
\hline & Ago & Set & Out & Nov & Dez & Jan & Fev & Mar & Abr & Mai & Jun & Jul \\
\hline T-e & 29,5 & 29,4 & 29,3 & 29,8 & 29,9 & 29,7 & 29,7 & 29,8 & 29,7 & 29,6 & 29,5 & 29,7 \\
T-s & 29,8 & 29,2 & 29,5 & 30,0 & 30,0 & 29,6 & 30,1 & 30,0 & 29,9 & 29,9 & 29,8 & 29,9 \\
DQO-e & 384,3 & 405,2 & 435,4 & 377,7 & 277,5 & 735,0 & 550,0 & 1183,3 & 995,8 & 962,8 & 1068,8 & 933,3 \\
DQO-s & 80,4 & 106,3 & 121,3 & 93,1 & 79,5 & 108,8 & 112,5 & 135,0 & 118,8 & 112,0 & 105,0 & 128,8 \\
DBO-e & 179,3 & 155,7 & 215,3 & 180,9 & 133,0 & 222,7 & 120,4 & 298,8 & 325,1 & 209,1 & 179,9 & 330,0 \\
DBO-s & 25,3 & 20,4 & 26,4 & 17,8 & 88,9 & 27,5 & 22,7 & 43,2 & 26,0 & 52,8 & 19,4 & 69,3 \\
OG-e & 79,4 & 55,7 & 47,8 & 35,5 & 30,4 & 8,7 & 15,2 & 27,6 & 81,5 & 43,8 & 31,1 & 47,4 \\
OG-s & 18,3 & 13,9 & 15,4 & 8,7 & 5,9 & 3,9 & 1,0 & 13,9 & 9,0 & 1,6 & 16,3 & 9,8 \\
pH-e & 6,4 & 6,7 & 6,6 & 6,8 & 7,0 & 5,8 & 5,9 & 6,0 & 6,6 & 5,7 & 6,7 & 5,8 \\
pH-s & 6,6 & 6,6 & 6,8 & 6,9 & 7,6 & 6,2 & 6,1 & 6,8 & 7,0 & 6,0 & 7,0 & 6,3 \\
SD60-e & - & - & - & - & - & - & - & - & - & - & - & - \\
SD60-s & 0,3 & 0,3 & 0,1 & 0,4 & 0,4 & 0,2 & 0,7 & 0,6 & 0,4 & 0,2 & 0,3 & 0,2 \\
CT-e & - & - & - & - & - & - & - & - & - & - & - & - \\
CT-s & 103,2 & 97,3 & 71,0 & 67,3 & 72,7 & 98,04 & 104,6 & 20,2 & 20,8 & 34,3 & 3,6 & 3,0 \\
& $\mathrm{x} 10^{3}$ & $\mathrm{x} 10^{4}$ & $\mathrm{x} 10^{3}$ & $\mathrm{x} 10^{3}$ & $\mathrm{x} 10^{3}$ & $\mathrm{x} 10^{4}$ & $\mathrm{x} 10^{4}$ & $\mathrm{x} 10^{4}$ & $\mathrm{x} 10^{4}$ & $\mathrm{x} 10^{5}$ & $\mathrm{x} 10^{5}$ & $\mathrm{x} 10^{5}$ \\
EC-e & - & - & - & - & - & - & - & - & - & - & - & - \\
EC-s & 9,4 & 8,7 & 6,8 & 7,3 & 7,1 & 9,17 & 7,0 & 6,05 & 5,9 & 8,1 & 1,2 & 1,3 \\
& $\mathrm{x} 10^{4}$ & $\mathrm{x} 10^{3}$ & $\mathrm{x} 10^{4}$ & $\mathrm{x} 10^{3}$ & $\mathrm{x} 10^{3}$ & $\mathrm{x} 10^{4}$ & $\mathrm{x} 10^{4}$ & $\mathrm{x} 10^{4}$ & $\mathrm{x} 10^{4}$ & $\mathrm{x} 10^{5}$ & $\mathrm{x} 10^{5}$ & $\mathrm{x} 10^{5}$ \\
\hline
\end{tabular}

$\mathrm{T}\left({ }^{0} \mathrm{C}\right)(-\mathrm{e}-\mathrm{s}) ; \mathrm{pH}(-\mathrm{e}-\mathrm{s}) ; \mathrm{OG}(\mathrm{mg} / \mathrm{L})(-\mathrm{e}-\mathrm{s}) ; \mathrm{SD} 60$ (mL/L) (-e-s); $\mathrm{DQO}\left(\mathrm{mgO}_{2} / \mathrm{L}\right)$ (-e-s); $\mathrm{DBO}\left(\mathrm{mgO}_{2} / \mathrm{L}\right)(-\mathrm{e}-\mathrm{s}) ; \mathrm{CT}(\mathrm{NMP} / 100 \mathrm{~mL})(-\mathrm{e}-\mathrm{s})$ e EC (-e-s) $(\mathrm{NMP} / 100 \mathrm{~mL})$.

$$
\text { -e (entrada); -s (saída) }
$$

Tabela 6: Resultados das Análises Físico-químicas e Microbiológicas para AM4.

\begin{tabular}{|c|c|c|c|c|c|c|c|c|c|c|c|c|}
\hline AM1 & & & 2020 & & & & & & 2021 & & & \\
\hline & Ago & Set & Out & Nov & Dez & Jan & Fev & Mar & Abr & Mai & Jun & Jul \\
\hline T-e & 28,7 & 28,9 & 28,9 & 29,5 & 29,3 & 29,9 & 29,6 & 29,3 & 29,5 & 29,4 & 29,5 & 29,4 \\
\hline T-s & 29,0 & 29,3 & 29,5 & 29,8 & 29,6 & 29,8 & 29,8 & 29,8 & 29,7 & 29,8 & 29,7 & 29,8 \\
\hline DQO-e & 303 & 820,7 & 575,6 & 605,0 & 1096,6 & 343,8 & 695,8 & 625,0 & 925,0 & 1204,3 & 770,8 & 1087,5 \\
\hline DQO-s & 50,5 & 65,68 & 32,0 & 43,3 & 86,0 & 66,3 & 127,9 & 87,5 & 153,8 & 200,3 & 115,3 & 190,3 \\
\hline DBO-e & 121,2 & 328,3 & 326,48 & 224,0 & 276,9 & 104,1 & 140,0 & 168,4 & 295,9 & 250,1 & 215,0 & 238,0 \\
\hline DBO-s & 20,2 & 26,26 & 40,15 & 86,00 & 70,1 & 22,3 & 49,5 & 88,2 & 23,3 & 62,0 & 52,7 & 87,5 \\
\hline OG-e & 27,5 & 41,8 & 31,8 & 29,0 & 49,5 & 13,0 & 8,3 & 46,3 & 22,3 & 30,1 & 39,5 & 48,8 \\
\hline OG-s & 11,4 & 16,4 & 17,7 & 18,2 & 14,1 & 1,1 & 2,3 & 26,6 & 3,9 & 15,3 & 18,8 & 23,0 \\
\hline pH-e & 5,8 & 6,1 & 6,2 & 6,2 & 6,6 & 6,0 & 6,0 & 6,7 & 5,0 & 6,0 & 6,7 & 6,0 \\
\hline pH-s & 5,2 & 6,7 & 7,0 & 7,0 & 7,2 & 6,4 & 6,1 & 6,9 & 5,5 & 6,5 & 7,0 & 6,1 \\
\hline SD60-e & - & - & - & - & - & - & - & - & - & - & - & - \\
\hline SD60-s & 0,1 & 0,2 & 0,6 & 0,2 & 1,0 & 2,0 & 0,2 & 0,3 & 0,1 & 0,5 & 0,4 & 0,5 \\
\hline CT-e & - & - & - & - & - & - & - & - & - & - & - & - \\
\hline CT-s & $\begin{array}{l}4,7 \\
\times 10^{4}\end{array}$ & $\begin{array}{l}87,04 \\
\times 10^{5}\end{array}$ & $\begin{array}{l}198,6 \\
\times 10^{5}\end{array}$ & $\begin{array}{l}34,4 \\
x 10^{5}\end{array}$ & $\begin{array}{l}68,6 \\
\times 10^{5}\end{array}$ & $\begin{array}{l}3,02 \\
\times 10^{5}\end{array}$ & $\begin{array}{c}30,9 \\
\times 10^{4}\end{array}$ & $\begin{array}{l}34,5 \\
\times 10^{5}\end{array}$ & $\begin{array}{l}35,8 \\
\times 10^{5}\end{array}$ & $\begin{array}{l}27,8 \\
x 10^{5}\end{array}$ & $\begin{array}{l}35,0 \\
\times 10^{5}\end{array}$ & $\begin{array}{l}3,7 \\
\times 10^{6}\end{array}$ \\
\hline EC-e & - & - & - & - & - & - & - & - & - & - & - & - \\
\hline EC-s & $\begin{array}{c}1,1 \\
\times 10^{4} \\
\end{array}$ & $\begin{array}{r}31,90 \\
\times 10^{5}\end{array}$ & $\begin{array}{r}19,37 \\
\times 10^{5} \\
\end{array}$ & $\begin{array}{c}9,3 \\
\times 10^{5} \\
\end{array}$ & $\begin{array}{r}13,7 \\
\times 10^{5} \\
\end{array}$ & $\begin{array}{l}1,01 \\
\times 10^{5}\end{array}$ & $\begin{array}{r}8,6 \\
\times 10^{4} \\
\end{array}$ & $\begin{array}{c}9,1 \\
\times 10^{5}\end{array}$ & $\begin{array}{c}6,4 \\
\times 10^{5} \\
\end{array}$ & $\begin{array}{r}8,9 \\
\times 10^{5} \\
\end{array}$ & $\begin{array}{r}18,1 \\
\times 10^{3} \\
\end{array}$ & $\begin{array}{c}1,1 \\
\times 10^{6}\end{array}$ \\
\hline
\end{tabular}


Figura 2: Resultados das Análises AM-1.

T; pH; OG; SD60; DQO; DBO; CT e EC.

-e (entrada); -s (saída)

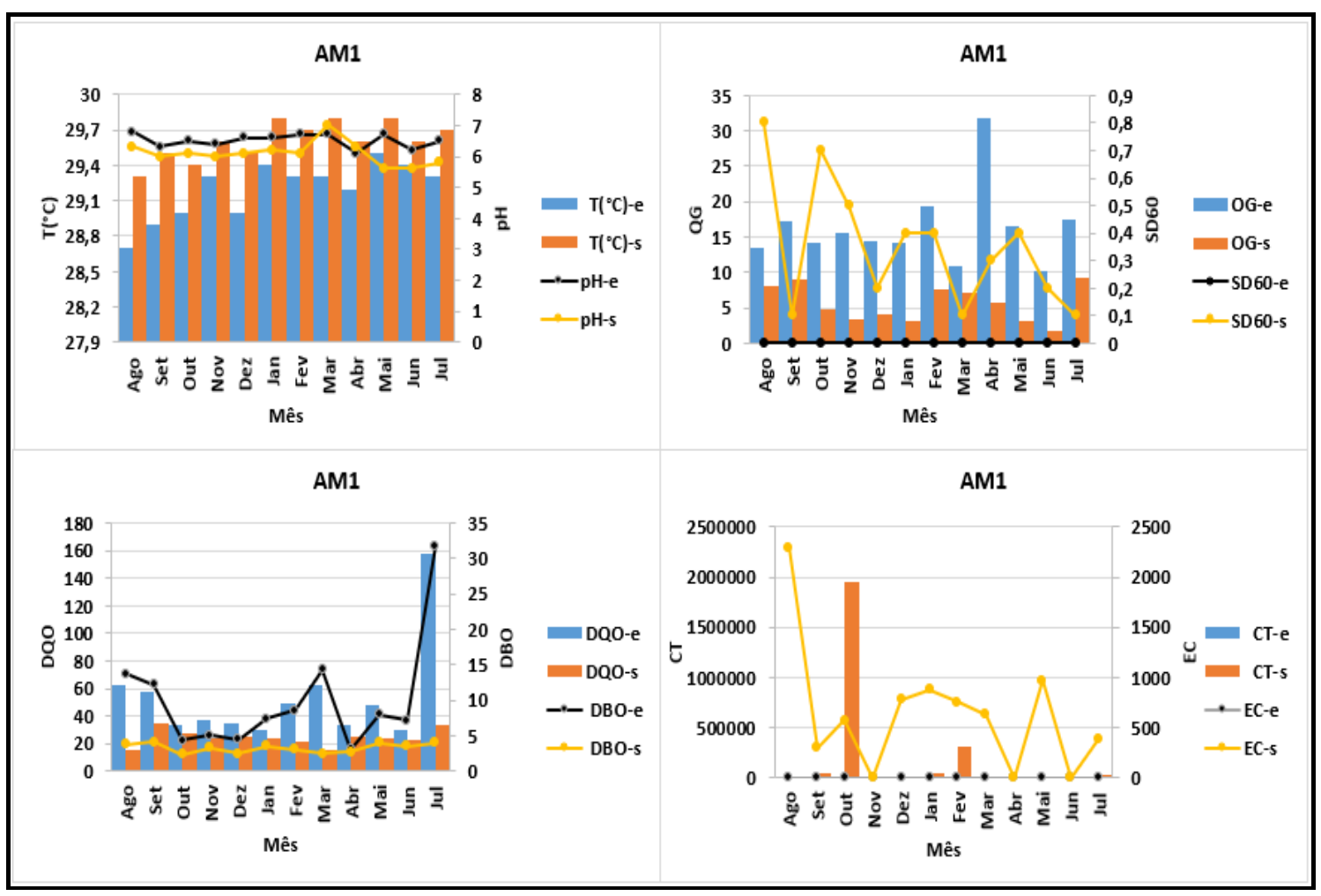

Figura 3: Resultados das Análises AM-2.

T; pH; OG; SD60; DQO; DBO; CT e EC.

-e (entrada); -s (saída)

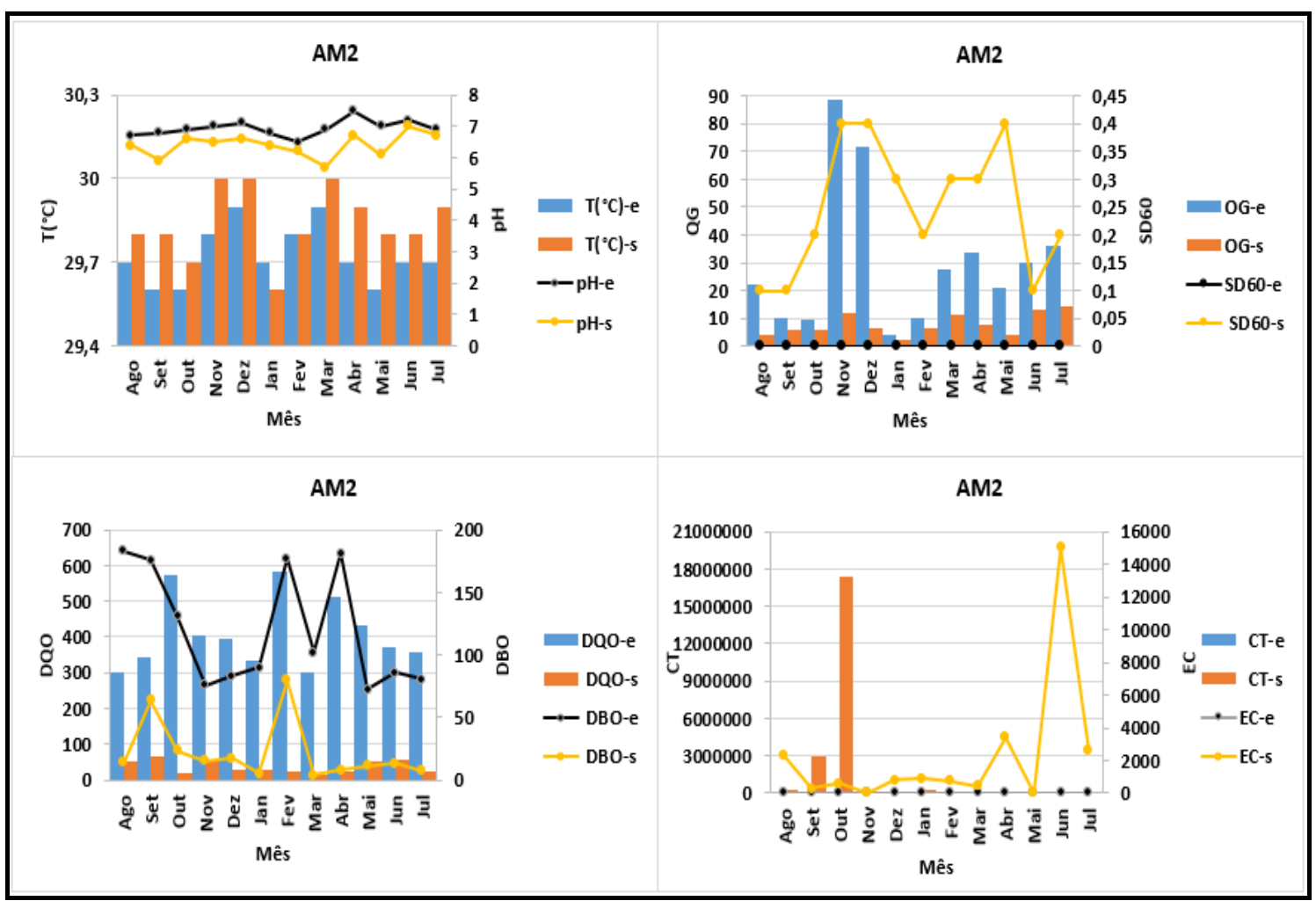


Figura 4: Resultados das Análises AM-3.

T; pH; OG; SD60; DQO; DBO; CT e EC.

-e (entrada); -s (saída)

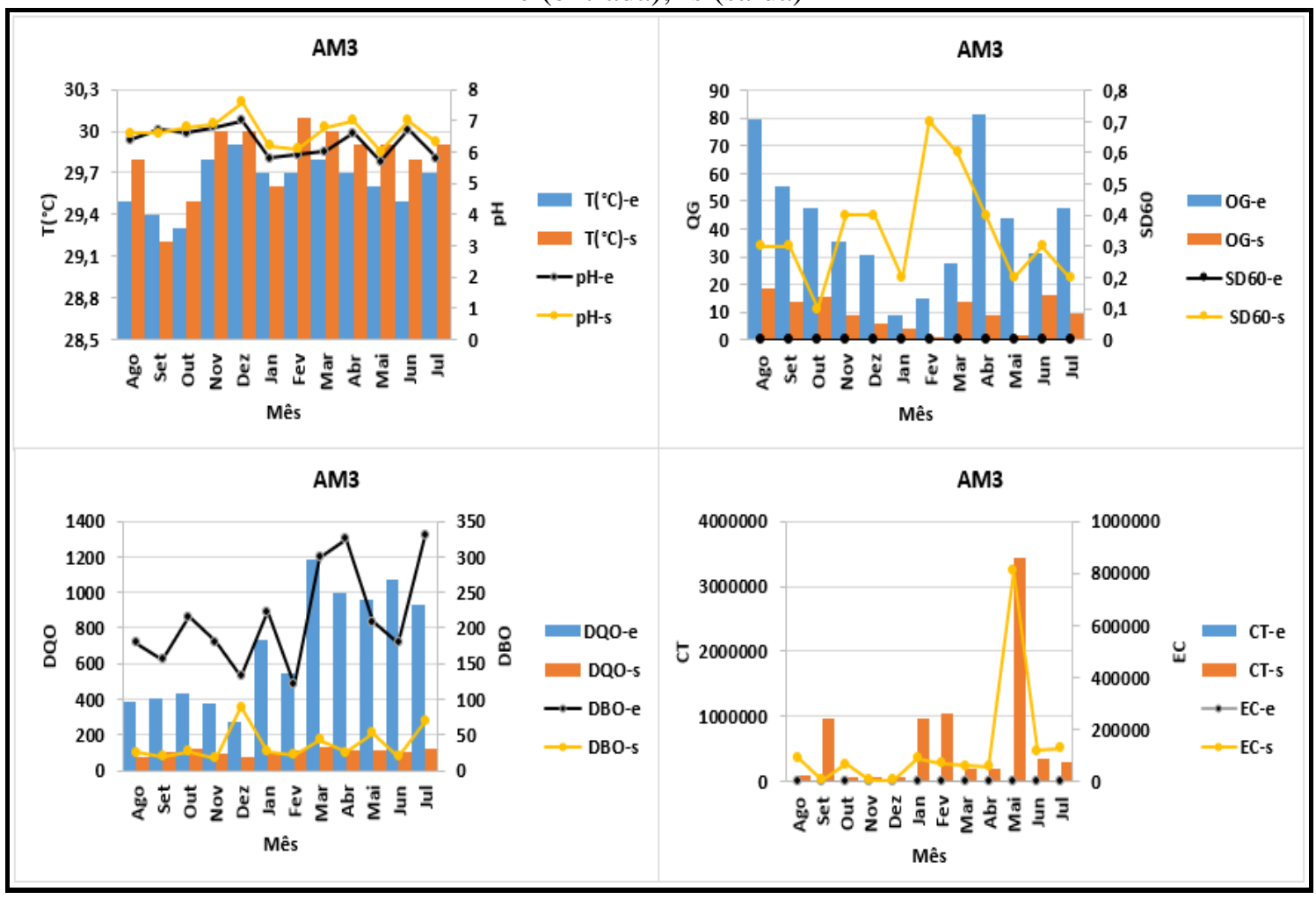

Figura 5: Resultados das Análises AM-4.

T; pH; OG; SD60; DQO; DBO; CT e EC.

-e (entrada); -s (saída)

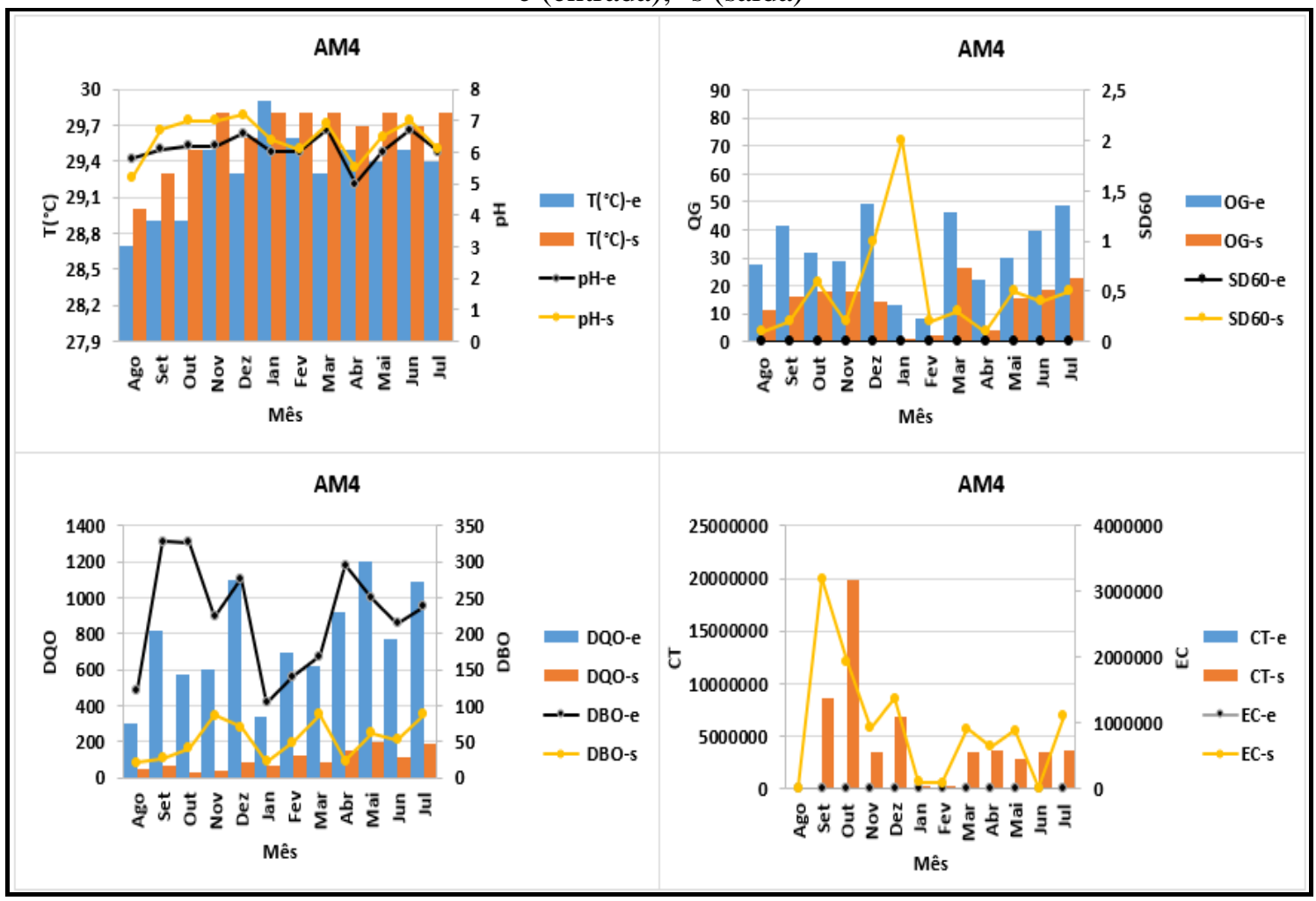


Nesta pesquisa, os valores obtidos para a temperature do efluente estão próximos de $30^{\circ} \mathrm{C}$ (ver Figuras 2, 3, 4 e 5) e se encontram em conformidade com as normas do CONAMA (2011), que estabelece uma temperature inferior a $40^{\circ} \mathrm{C}$, e a variação de temperatura $\pm 3^{\circ} \mathrm{C}$. De acordo com Melo et al. (2021) foram obtidos em suas pesquisas, antes e após o tratamento em esgoto doméstico por um reator UASB, variações de temperatura também próximos de $30^{\circ} \mathrm{C}$. Outras pesquisas envolvendo wetlands construídos de escoamento vertical (WCV) apresentaram em seus resultados variações de temperatura do efluente doméstico entre $15-27^{\circ} \mathrm{C}$ (METCALF; EDDY, 2016).

A Demanda Bioquímica de Oxigênio (DBO) esta presente em amostras de esgoto domestic, e, pode ser determinada de acordo com o valor de oxigênio absorvido pelos microrganismos, que são encontrados nestas amostras de efluentes reais. O limite máximo estabelecido é de até $120 \mathrm{mg} / \mathrm{L}$ de DBO por amostra, podendo aumentar desse valor, quando no sistema de tratamento, o efluente apresentar eficiência de remoção mínima de 60\% de DBO (CONAMA, 2011). Nesta pesquisa, os valores encontrados de DBO (Figuras 2, 3, 4 e 5) estão abaixo de 120 $\mathrm{mg} / \mathrm{L}$ e variando entre $2,4-88,9 \mathrm{mg} / \mathrm{L}$, após o tratamento deste efluente, na saída do reator UASB. Melo et al. (2021) mostrou em amostras de efluentes de esgoto doméstico coletados na Região Metropolitana do Recife, após tratamento em reator UASB, valores de DBO entre 5,039,0 mg/L, estando de acordo com os limites estabelidos pelo CONAMA (2011).

A Demanda Química de Oxigênio (DQO) é uma forma de se obter o percentual de Oxigênio Dissolvido (OD), a partir da degradação da material orgânica quando absorve esse OD em pH ácido. A partir carga orgânica bruta e de acordo com as normas ambientais, o descarte de efluentes devem apresentar um valor de 100-200 $\mathrm{mgO}_{2} / \mathrm{L}$. Os resultados apresentados das DQOs (15-198,0 $\mathrm{mgO}_{2} / \mathrm{L}$ ), após tratamento em reator UASB, conforme as Figuras 2, 3, 4 e 5, mostram que o esgoto doméstico analisado nesta pesquisa se encontram de acordo com as legislações estabelecidas na Resolução $430^{\circ}$ do CONAMA de 2011. Melo et al. (2021) em suas pesquisas de campo, e após coleta do esgoto doméstico bruto na saída de uma estação de tratamento em reator UASB, obteve em seus resultados, valores próximos de DOQ entre 32,9$100,0 \mathrm{mgO}_{2} / \mathrm{L}$.

Uma pesquisa divulgada na literatura mostrou uma eficiência na remoção de DQO de uma estação de tratamento de esgoto (ETE) entre 80 e $86 \%$, após o uso do reator UASB. Esses resultados mostram estar dentro do cumprimento das legislações ambientais, no que se refer ao descarte correto de esgoto doméstico no meio ambiente (WAGNER et al., 2019). Outras pesquisas utilizando os wetlands construídos (WC) mostram a eficiência, que este tratamento apresenta para os efluentes descartados no meio ambiente, por pessoas que vivem em situações críticas e desfavorecidas economicamente. De acordo com Decezaro et al. (2021) relataram em suas pesquisas envolvendo o $\mathrm{WC}$, uma alta eficiência de DQO de aproximadamente $80 \%$, sendo considerada carga orgânica ainda elevada em seu esgoto doméstico. Nesta pesquisa, valores 
entre $44-49 \%$ foram apresentados para $\mathrm{DBO}_{5}$ e DQO, respectivamente. Nos estudos que utilizam o WC também foram observados resultados reduzidos da matéria orgânica, quando o WC é substituído por brita em vez de areia (NIVALA et al., 2013; BOHÓRQUEZ et al., 2017).

As substâncias orgânicas presentes em animais, minerais e vegetais, costumam ser definidas como óleos e graxas (OG). E, quando essas susbtâncias são descartadas de forma inadequada no meio ambiente sem um tratamento prévio, podem acarretar riscos afetando também a saúde da população. As normas ambientais do CONAMA (2011), estabelece o limite de até $100 \mathrm{mg} / \mathrm{L}$ para os parâmetros de OG. Nesta pesquisa foram encontradas valores de OG entre 1,0-26,6 $\mathrm{mg} / \mathrm{L}$ na saída da estação de tratamento em reator UASB (ver Figuras 2, 3, 4 e 5), valores que estão de acordo com as normas ambientais do CONAMA (2011). Melo et al. (2021) mostraram, que em suas pesquisas, a quantidade de $\mathrm{OG}$ variou entre $0-12,1 \mathrm{mg} / \mathrm{L}$ em amostras de esgoto doméstico, quando foram coletadas após serem tratadas na saída da estação do reator UASB.

Os Sólidos Decantáveis (SD)60 representam uma das séries de sólidos que são identificados quando $1 \mathrm{~L}$ da amostra prevalecer durante uma hora no Cone de Imhoff, de acordo com os padrões de qualidade descritos na Resolução CONAMA (2011), podendo apresentar até 1mL/L de materiais sedimentáveis. Neste estudo, os resultados das análises nas amostras de esgoto doméstico apresentados, mostraram valores entre 0,1-0,8 mL/L (ver Figuras 2, 3, 4 e 5), onde apenas 1 amostra apresentou valor superior $(>1 \mathrm{~mL} / \mathrm{L})$ no mês de Janeiro/2021, após o tratamento na saída do reator UASB. Esses valores encontrados estão dentro das normas e vigências estabelecidas pelas legislações ambientais (CONAMA, 2011). De acordo com Melo et al. (2021) foram analisados em suas pesquisas após tratamento do efluente em reator UASB, os valores de SD60 variando próximos de 0,1-0,9 $\mathrm{mL} / \mathrm{L}$.

$\mathrm{O}$ potencial Hidrogeniônico, também conhecido como $\mathrm{pH}$ de uma amostra, determina a quantidade de íons hidrogênio $\left(\mathrm{H}^{+}\right)$, capaz de identificar o grau de acidez, neutralidade ou alcalinidade presentes nesta solução. Na análise de esgoto doméstico, de acordo com as normas vigentes na legislação CONAMA (2011), o pH de uma amostra deve estar entre 5 e 9 . Nesta pesquisa, o valor obtido do $\mathrm{pH}$ various entre 5,2-7,2 (ver Figuras 2, 3, 4 e 5), ainda entando dentro do limite das exigências vigentes das legislações ambientais. Esses resultados de pH foram encontrados na saída do reator UASB, após tratamento de toda a amostra do efluente. Dados publicados na literatura mostraram em amostras de esgoto doméstico, após serem tratadas em reator UASB e analisadas, valores de $\mathrm{pH}$ variando entre 5,5 à 7,2 na saída da estação de tratamento (MELO et al., 2021).

Uma das maneiras de se determinar os coliformes totais em uma amostra ambiental é através das análises microbiológicas. Esses tipos de microorganismos costumam estarem presentes naturalmente no meio ambiente e também no trato gastrointestinal de alguns animais, principalmente na forma de bacilos dos tipos aeróbios ou anaeróbios. De acordo com a Resolução 430\%/2011 do CONAMA, não existe limite estabelecido sobre à concentração de 
coliformes totais presentes em uma amostra ambiental, o que difere das legislações anteriores, que costumavam informar em suas normas, que a ausência desses coliformes totais deveriam prevalecerem (CONAMA, 2011). Neste estudo, foram investigados em amostras de efluentes reais de esgoto doméstico, a quantidade presentes de coliformes totais e coliformes termotolerantes, sendo este último investigado através principalmente pela presença da Escherichia Coli (E.C.), que representa as contaminações fecais e de patógenos. Os valores encontrados de coliformes totais e de Escherichia Coli no referido estudo, nas amostras de efluentes reias variaram entre $0-172,6 \times 10^{2} \mathrm{NMP} / 100 \mathrm{~mL}$ e $0-9,7 \times 10^{2} \mathrm{NMP} / 100 \mathrm{~mL}$, respectivamente. Esses resultados encontrados foram observados nas amostras coletados na saída da estação de tratamento. Melo et al. (2021) em suas pesquisas de campo, e após coleta do esgoto doméstico bruto na saída de uma estação de tratamento em reator UASB, obteve em seus resultados, valores próximos de coliformes totais e de Escherichia Coli no referido estudo variando entre $0-8,9 \times 10^{5} \mathrm{NMP} / 100 \mathrm{~mL}$ e $0-8,6 \times 10^{4} \mathrm{NMP} / 100 \mathrm{~mL}$, respectivamente. No Brasil atualmente ainda não existe nenhum limite para as concentrações desses microorganismos em efluentes. Em trabalhos recentes realizados com ETA's convencionais, foi analisado o domínio da sazonalidade sobre estas estações de tratamentos de esgoto doméstico, na cidade de Gambella, na Etiópia com uma vazão do afluente na ordem de $116 \mathrm{~L}^{-1}{ }^{-1}$ (BIRHANE et al., 2019). Dados divulgados pela Organização Mundial da Saúde mostraram resultados de E. Coli em efluentes contidos nas ETA's fora dos limites estabelecidos com o padrão de potabilidade dessa organização (WHO, 2011).

\section{Teste de Toxicidade}

As análises a seguir mostram os resultados dos ensaios de fitotoxicidade, que foram obtidos a partir do planejamento fatorial $2^{2}$ para as variáveis de entrada: Concentração da Amostra (CA$\%)$ e do valor de $\mathrm{pH}$; sendo as variáveis de saída: Comprimento médio da Raiz (CR-mm), Índices de Crescimento Radicular (ICR) e Índices de Germinação (IG-\%) das amostras.

O controle negativo com uso da água destilada serviu para obter a média de crescimento da semente de pimentão, representando praticamente o branco da amostragem. Entretanto, o controle positivo com a testagem da solução de sulfato de Zinco serviu para provar que a semente de pimentão de fato não irá germinar. A Figura 6 apresenta o controle negativo e o positivo realizados com água destilada e sulfato de $\mathrm{Zinco}\left(\mathrm{ZnSO}_{4}\right)$, respectivamente.

Figura 6: Teste de controle negativo e o positivo. 


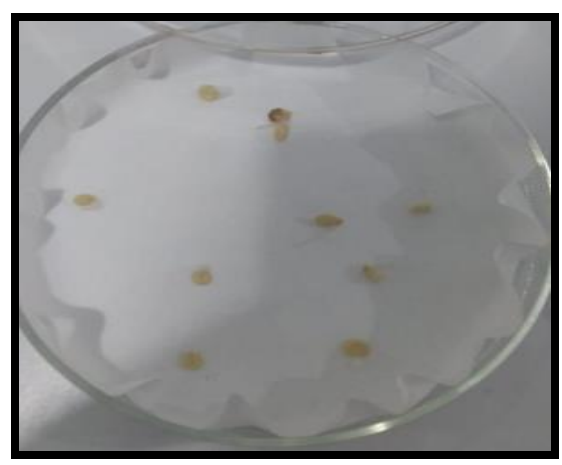

Controle Negativo Água $\left(\mathrm{H}_{2} \mathrm{O}\right)$ Destilada

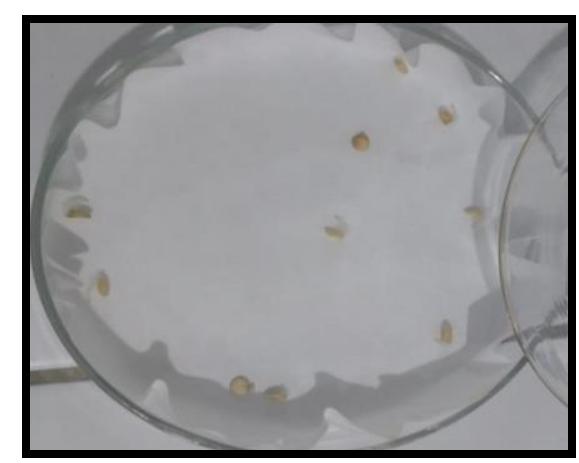

Controle Positivo-

Sulfato de Zinco $\left(\mathrm{ZnSO}_{4}\right)$

Os resultados obtidos em amostras de esgoto doméstico, antes do tratamento no reator UASB, em relação à fitotoxicidade (entrada), mostram que todos os ensaios utilizando a semente de Capsicum annum L. analisadas, apresentaram índice de germinação abaixo de $100 \%$, onde apenas 6,67\% das amostras apresentaram índice de germinação entre $80 \%$ e 120\%, que é considerado um valor padrão. E, cerca de 93,33\% das amostras, apresentaram índice de germinação abaixo de $80 \%$, indicando a presença de substâncias que inibem o crescimento da semente, segundo Young et al. (2012).

Os valores analisados em amostras de esgoto doméstico, após tratamento no reator UASB, em relação à fitotoxicidade (saída) utilizando a semente de Capsicum annum L., mostraram que cerca de $83,33 \%$ dos ensaios, apresentaram resultados para índice de germinação abaixo de $80 \%$, enquanto que, apenas $16,67 \%$ apresentaram índice de germinação entre $80 \%$ e $120 \%$. Esses resultados após o tratamento em reator UASB comprovam uma melhoria em relação ao índice de germinação de cerca de $10 \%$.

As Figuras 7, 8 e 9 mostram as amostras de esgoto doméstico real, antes e após o tratamento no reator UASB, em relação à fitotoxicidade de entrada e saída, respectivamente.

A Figura 7 representa a Concentração da Amostra (CA) igual a 33,33\%, 66,66\% e 99,99\% e um valor de $\mathrm{pH}$ igual a 3,25, de acordo com o planejamento experimental. Nesta foi observada, que na entrada do efluente tratado, a amostra AM-1 apresentou praticamente um dos maiores valores de Crescimento Radicular ( $C R=4,0 \mathrm{~mm}$ ), ICR igual a 0,8 e IG igual a 60\%. Na saída do efluente tratado, a amostra AM-2 também apresentou os maiores valores de CR=4,66 mm, ICR igual a 0,932 e IG igual a $104,85 \%$.

A Figura 8 representa a CA igual a 33,33\%, 66,66\% e 99,99\% e um valor de pH igual a 6,5, de acordo com o planejamento experimental. Nesta foi observada, que na entrada do efluente tratado, a amostra AM-1 também apresentou o maior valor de CR igual a 6,0 mm, ICR de 1,2 e IG de 90\%. Na saída do efluente tratado, a amostra AM-2 também apresentou o maior valor de CR igual a 5,625 mm, ICR de 1,125 e IG de $98,43 \%$. 
Figura 7: Ensaio de fitotoxicidade (entrada e saída)

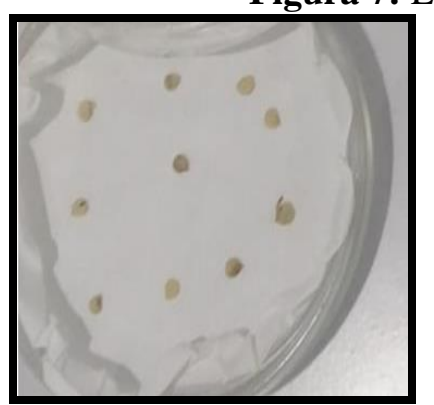

$\mathrm{pH}=3,25 ; \mathrm{C}(\%)=33,33 \%$. Entrada

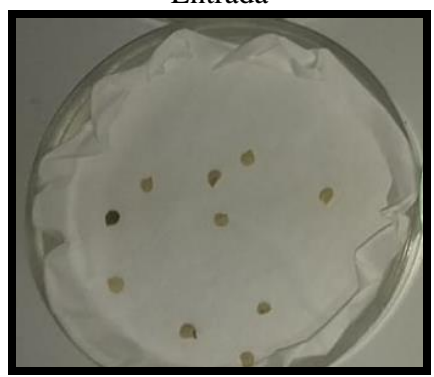

$\mathrm{pH}=3,25 ; \mathrm{C}(\%)=33,33 \%$.

Saída

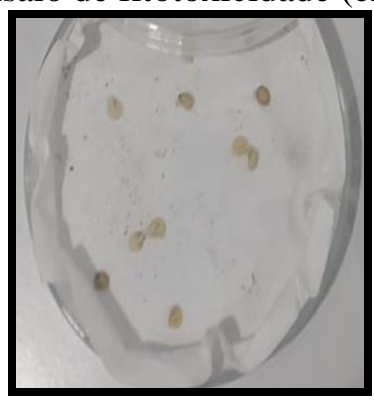

$\mathrm{pH}=3,25 ; \mathrm{C}(\%)=66,66 \%$.

Entrada

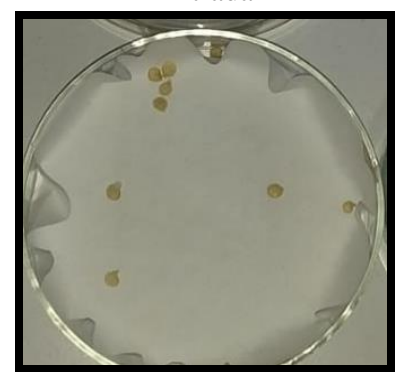

$\mathrm{pH}=3,25 ; \mathrm{C}(\%)=66,66 \%$. Saída

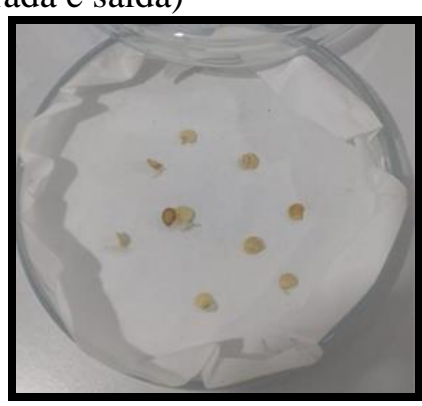

$\mathrm{pH}=3,25 ; \mathrm{C}(\%)=99,99 \%$. Entrada

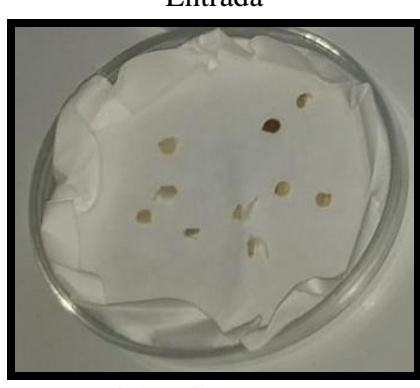

$\mathrm{pH}=3,25 ; \mathrm{C}(\%)=99,99 \%$. Saída

Figura 8: Ensaio de fitotoxicidade (entrada e saída)

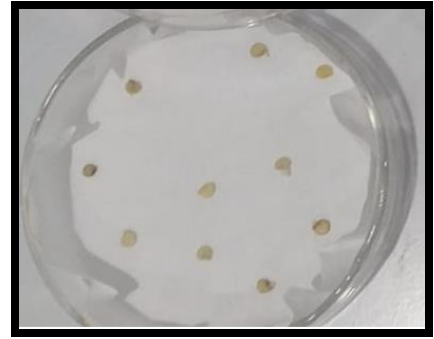

$\mathrm{pH}=6,50 ; \mathrm{C}(\%)=33,33 \%$. Entrada

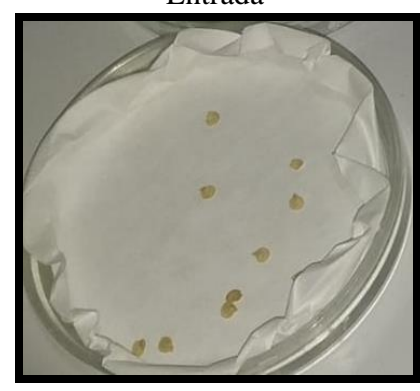

$\mathrm{pH}=6,50 ; \mathrm{C}(\%)=33,33 \%$. Saída

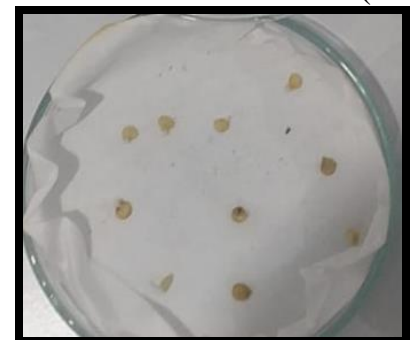

$\mathrm{pH}=6,50 ; \mathrm{C}(\%)=66,66 \%$. Entrada

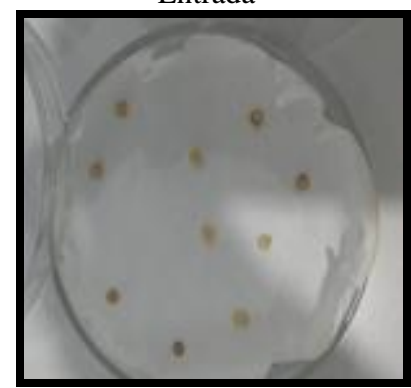

$\mathrm{pH}=6,50 ; \mathrm{C}(\%)=66,66 \%$. Saída

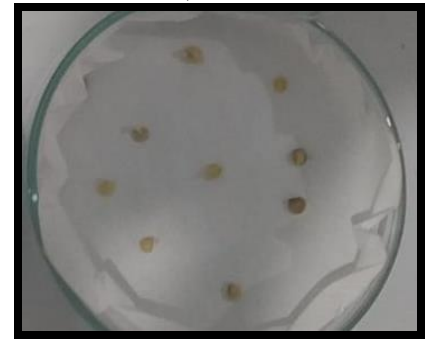

$\mathrm{pH}=6,50 ; \mathrm{C}(\%)=99,99 \%$ Entrada

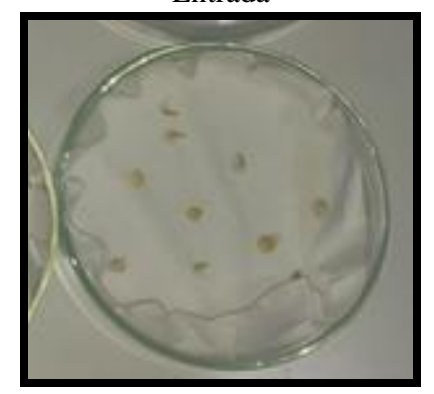

$\mathrm{pH}=6,50 ; \mathrm{C}(\%)=99,99 \%$.

Saída

A Figura 9 representa a CA igual a 33,33\%, 66,66\% e 99,99\% e um valor de $\mathrm{pH}$ igual a 9,75 , de acordo com o planejamento experimental. Nesta foi observada, que na entrada do efluente tratado, a amostra AM-1 mais uma vez apresentou o maior valor de CR igual 7,8 mm, ICR de 1,56 e IG de 97,5\%. Na saída do efluente tratado, a amostra AM-2 também mais uma vez apresentou o maior valor de CR igual 4,5 mm, ICR de 0,9 e IG de 90,0\%, embora esses resultados foram observados na CA igual a $66,66 \%$. 
Figura 9: Ensaio de fitotoxicidade (entrada e saída)

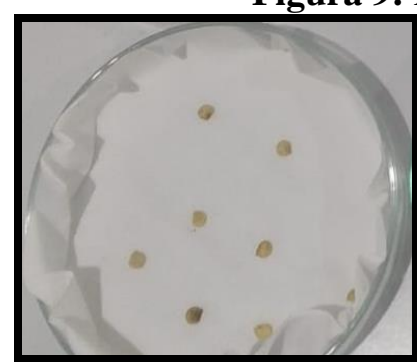

$\mathrm{pH}=9,75 ; \mathrm{C}(\%)=33,33 \%$.

Entrada

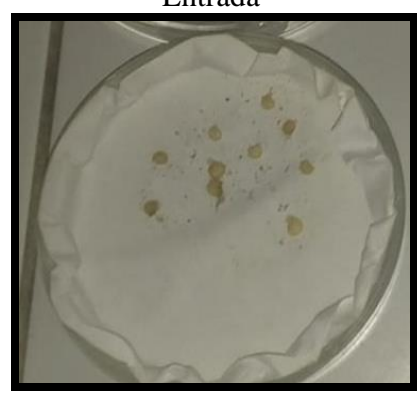

$\mathrm{pH}=9,75 ; \mathrm{C}(\%)=33,33 \%$.

Saída

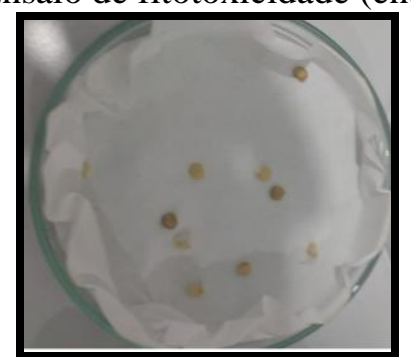

$\mathrm{pH}=9,75 ; \mathrm{C}(\%)=66,66 \%$.

Entrada

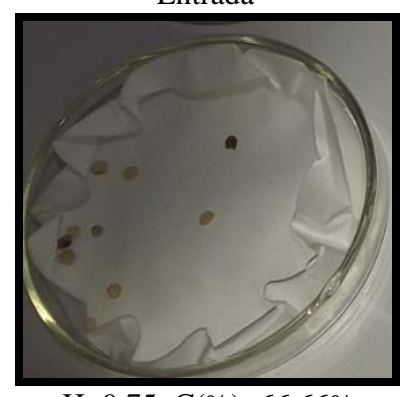

$\mathrm{pH}=9,75 ; \mathrm{C}(\%)=66,66 \%$.

Saída

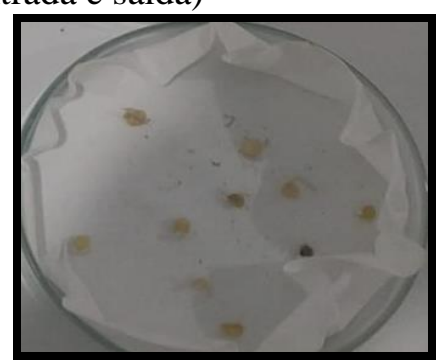

$\mathrm{pH}=9,75 ; \mathrm{C}(\%)=99,99 \%$.

Entrada

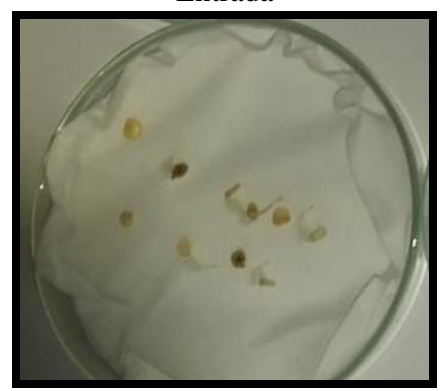

$\mathrm{pH}=9,75 ; \mathrm{C}(\%)=99,99 \%$.

Saída

De maneira geral, os resultados totais obtidos mostram que, $87,87 \%$ das amostras apresentaram IG (índice de germinação) inferior a $80 \%$, enquanto 12,13\% apresentaram IG entre $80 \%$ e $120 \%$. Os resultados obtidos antes do tratamento mostram que, em relação à porcentagem de amostra, apenas $16,66 \%$ das amostras puras $(99,99 \%)$ apresentaram IG entre $80 \%$ e $120 \%$. Os resultados obtidos após o tratamento mostram que $8,33 \%$ de amostras com concentração de 33,33\%, 16,66\% das amostras com concentração de 66,66\% e 25\% das amostras puras $(99,99 \%)$ apresentaram resultados de IG satisfatórios. Os resultados obtidos para o pH mostram que, $25 \%$ das amostras com pH 3,25, 8,33\% das amostras com pH 6,50 e 16,66\% das amostras com pH 9,75 apresentam índice de germinação ideal. Com base nos dados obtidos foi analisado que, quanto maior a concentração da amostra na maioria dos ensaios, as CA igual a 99,99\% apresentaram os melhores índices percentuais de IG. Entretanto, os valores de pH de 6,50 e 9,75 variaram o IG para a entrada de $90 \%$ e 97,5\%, respectivamente. Esses valores apresentados nas amostras para o IG, antes do tratamento são considerados ideais. Na saída, os valores de $\mathrm{pH}$ de 6,50 e 9,75 variaram o IG de 98,43\% e 80\%. Assim, foi observado que os resultados de IG após o tratamento são melhores com o valor de pH igual a 3,25, pois o IG foi de $104,85 \%$. Segundo a pesquisa de Sarafi et al. (2017), as sementes de Capsicum annum L. são moderadamente sensíveis a alguns compostos como o boro, por exemplo, reduzindo a taxa de fotossíntese da planta. Além disso, o estudo realizado Islek et al. (2015) comprovam que essas sementes são muito sensíveis ao cobre. $\mathrm{O}$ excesso de $\mathrm{Cu}$ pode interferir em inúmeros processos, tais como a fotossíntese, a síntese de pigmentos, o metabolismo de nitrogênio e das proteínas, a integridade de membrana e a absorção de minerais (YRUELA, 2009). Melo et al. (2021) observaram em sua pesquisa para os ensaios de fitotoxicidade com amostras de esgoto 
doméstico real, que as amostras na saída da estação de tratamento do reator UASB apresentaram 16,6\% de IG (Índice de Germinação) < 80\% e 69,4\% de IG> 120\%, o que indica a presença de substâncias que estimulam a germinação das sementes de alface "Lactuca sativa". Nos seus ensaios a germinação a radícula mostrou valores com tamanho médio igual ou superior a $5 \mathrm{~mm}$.

\section{CONCLUSÃO}

As amostras de esgoto doméstico real, que foram coletadas e investigadas neste estudo apresentaram as suas características, de acordo com as análises físico-química, microbiológico e os testes de fitotoxicidade. Os valores das análises físico-químicas obtidas nesta pesquisa atendem o cumprimento estabelecido nas normas das legislações ambientais, referente à Resolução 430\%/2011 do CONAMA. Os resultados mostrados para as análises microbiológicas, no que se refere às concentrações de coliformes totais e termotolerantes foram elevados, porém no Brasil não existe nenhuma restrição para essa análise. Nos ensaios de fitotoxicidade, os dados investigados mostraram que, $83,33 \%$ das amostras apresentaram IG (índice de germinação) inferior a $80 \%$, enquanto $16,67 \%$ apresentaram IG entre $80 \%$ e $120 \%$. O IG demonstra o crescimento que a semente de pimentão apresentou nos ensaios laboratoriais. $\mathrm{O}$ saneamento básico é de suma importância para a sociedade, e o tratamendo adequado desses resíduos antes de serem descartados no meio ambiente reduzem esses riscos. Assim, a necessidade da utilização de tecnologias capazes de tratar de forma adequada e ambientalmente correta esses efluentes. Os reatores do tipo UASB, têm sido bastante empregados com a finalidade de melhorar a eficiência de seus processos nas estações de tratamento de esgoto doméstico. Logo, nesta pesquisa, o uso desses reatores mostrou ser muito eficaz, sendo possível observar em alguns condomínios, o tratamento dos esgotos antes de serem descartados no meio ambiente.

\section{REFERÊNCIAS}

AFZAL, M., ARSLAN, M., MÜLLER, J.A., SHABIR, G., ISLAM, E., TAHSEEN, R., ANWAR-UL-HAQ, M., HASHMAT, A.J., IQBAL, S., KHAN, Q.M. Floating treatment wetlands as a suitable option for large-scale wastewater treatment. Nature Sustainability. v. 2, p. 863-871, 2019.

ALCARAZ-IBARRA, S.; MIER-QUIROGA, M.A.; ESPARZA-SOTO, M.; LUCEROCHÁVEZ, M.; FALL, C. Treatment of chocolate-processing industry wastewater in a low-temperature pilot-scale UASB: Reactor erformance and in-situ biogas use for bioenergy recovery. Biomass and Bioenergy. v. 142, p. 105786, 2020.

APHA. AMERICAN PUBLIC HEALTH ASSOCIATION. Standard Methods for the Examination of Water and Wastewater. 14 ${ }^{\mathrm{a}}$ ed. New York, 1975. 
APHA AMERICAN PUBLIC HEALTH ASSOCIATION. Standard Methods for the Examination of Water and Wastewater. 19ª ed. Washington, 1995.

APHA AMERICAN PUBLIC HEALTH ASSOCIATION. Standard Methods for the Examination of Water and Wastewater, $18^{\mathrm{a}}$ ed. New York, 2005.

BASSETT, J. VOGEL. Análise Inorgânica Quantitativa. $4^{\mathrm{a}}$ ed. Rio de Janeiro. Editora Guanabara S/A. 1981.

BATAlHA, B.L. Controle de Qualidade da Água para Consumo Humano. São Paulo. CETESB, 1977.

BIRHANE, B.S.; HISHE, T.G.; TENAGASHAW, D.Y. Performance Evaluation of Gambella Town Water Treatment Plant. International Journal of Advanced Science and Engineering, v. 6, n. 2, p. 1305-1312, 2019.

BISOGNIN, D.A.; VELASQUEZ, L.; WIDDERS, I. Cucumber seedling dependence on cotyledonary leaves for early growth. Pesquisa Agropecuária Brasileira, v.40, n. 6 , p.531-539, 2005.

BITOUN, J.L.I.B. A Região Metropolitana do Recife: Principais características da sua região de influência e da integração dos municípios na aglomeração recifense. In: Maria Ângela de Almeida Souza; Jan Bitoun. (Org.). RECIFE: TRANSFORMAÇÕES NA ORDEM URBANA. 1ed ${ }^{\text {a }}$. Rio de Janeiro: Letra Capital, v. 6, p. 45-69, 2015.

BOHN, P.W.; MARIÑAS, B.J.; GEORGIADIS, J.G.; MAYES, A.M.; SHANNON, M.A.; ELIMELECH, M. Science and technology for water purification in the coming decades. Nature. v. 452, p. 7185, 301-310, 2008.

BOHÓRQUEZ, E.; PAREDES, D.; ARIAS, C.A. Vertical flow-constructed wetlands for domestic wastewater treatment under tropical conditions: effect of different design and operational parameters. Environmental Technology, v. 38, n. 2, p. 199-208, 2017.

BORTH, P.L.B.; GALVÃO, R.B.; SAMPAIO, L.P.; TORRECILHAS, A.R.; FERNANDES, F. Congresso ABES, Tratamento Conjugado de Esgoto Doméstico e Lixiviado de Aterro Sanitário em Reatores Anaeróbios de Manta de Lodo, 2017.

BRANDÃO Y.; TEODOSIO J.; BENACHOUR M.; OLIVEIRA J.; MARINHO I.; FIGUEIRÊDO F.; ANSELMO-FILHO P. Estudo do efeito do excesso de ar e da potência dissipada do queimador sobre as capacidades do processo DiCTT no tratamento de efluentes líquidos fenólicos. Revista Ibero-Americana Sistemas Cibernética e Informática. v. 7, p. 1-9, 2010.

BRANDÃO, Y.B.; TEODISIO, J.R.; SILVA, A.V.V.; OLIVEIRA, J.G.C.; BISPO, A. M.; VASCONCELOS, W.E.; BENACHOUR, M. Processo de Oxidação Termoquímica DiCTT: Aplicação no Tratamento de Efluentes Líquidos Fenólicos e Modelagem via Redes Neurais Artificiais. In: VI Encontro sobre aplicações Ambientais de Processos Oxidativos Avançados, 2011, Rio de Janeiro, RJ. Resumos expandidos. Rio de Janeiro, RJ: EPOA, 2011. 
BRANDÃO Y.; TEODOSIO J.; DIAS F.; EUSTÁQUIO W.; BENACHOUR M. Treatment of phenolic effluents by a thermochemical oxidation process (DiCTT) and modelling by artificial neural networks. Fuel. v. 110, p. 185-195, 2013.

BRANDÃO, Y.B.; OLIVEIRA, J.G.C.; BENACHOUR M. Phenolic Wastewaters: Definition, Sources and Treatment Processes. In: Soto-Hernández M, Palma-Tenango M, Gárcia-Mateos MR (Ed). Phenolic compounds: natural sources, importance and applications, 1 rd edn. Intech, Rijeka-Croatia, p. 323-342, 2017.

BRANDÃO, Y.B.; DIAS, F.F.S.; OLIVEIRA, D.C.; ZAIDAN, L.E.M.C.; TEODOSIO, J.R.; OLIVEIRA, J.G.C.; BENACHOUR, M. Unconventional advanced oxidation technique: Evaporation liquid rate and phenolic compounds degradation evaluation and modelling/optimization process with CFD, RSM and ANNs. Fuel. v. 300, p. 120967, 2021.

BRASIL. (2013) Ministério das Cidades. Secretaria Nacional de Saneamento Ambiental. Plano Nacional de Saneamento Básico Brasília: Ministério das Cidades . Disponível em: <Disponível em:

http://www.cidades.gov.br/images/stories/ArquivosSNSA/Arquivos_PDF/plansab_0612-2013.pdf >. Acesso em: 19 jan. 2021.

CARCARÁ, M.S.M.; SILVA, E.A.; MOITA NETO, J.M. Saneamento básico como dignidade humana: entre o mínimo existencial e a reserva do possível. Engenharia Sanitária e Ambiental. 24, n. 3, 2019.

CARUSO, B.A.; FREEMAN, M.C. Shared sanitation and the spread of COVID-19: risks and next steps. The Lancet. Planetary Health, v. 4, n. 5, 2020.

https://doi.org/10.1016/s2542-5196(20)30086-3.

CHERNICHARO, C.A.L. Princípios do Tratamento Biológico de Águas Residuárias: Reatores Anaeróbios. 2. ed. Belo Horizonte: UFMG, 2016.

CONAMA. Resolução n 430/2011. MMA, 2011. Disponível em: <Resolução CONAMA No 430/2011 - "Dispõe sobre condições e padrões de lançamento de efluentes, complementa e altera a Resolução no 357, de 17 de março de 2005, do Conselho Nacional do Meio Ambiente - CONAMA." (mma.gov.br)>. Acesso em: 15 de fev. de 2021.

DECEZARO, S.T.; WOLFF, D.B.; ARAÚJO, R.K.; CARVALHO JÚNIOR, O.; SEZERINO, P.H. Nitrification/denitrification potential of a septic tank and a constructed wetland with recirculation in the decentralized wastewater treatment from a housing development. Engenharia Sanitária e Ambiental. v. 26, p. 4, 2021.

DING, W.; JIN, W.; CAO, S.; ZHOU, X.; WANG, C.; JIANG, Q.; HUANG, H.; TU, R.; HAN, S-F; WANG, Q. Ozone disinfection of chlorine-resistant bacteria in drinking water. Water Research. v. 160, p. 339-349, 2019.

FERRI, L.S.R. Caracterização de esgoto oriundo de fossa séptica biodigestora e seu potencial para aplicação na agricultura como biofertilizante. $2014.67 \mathrm{f}$. Trabalho de 
Conclusão de Curso (TCC) - Universidade Tecnológica Federal do Paraná, Campus Francisco Beltrão, 2014.

GASSIE, L.W., ENGLEHARDT, J.D. Advanced oxidation and disinfection processes for onsite net-zero greywater reuse: a review. Water Research. v. 125, p. 384-399, 2017.

GU, J.; HAN, B.; WANG, J. COVID-19: Gastrointestinal Manifestations and Potential Fecal-Oral Transmission. Gastroenterology. v. 158, n. 6, p. 1518-1519, 2020.

GWENZI, W. Leaving no stone unturned in light of the COVID-19 faecal-oral hypothesis? A water, sanitation and hygiene (WASH) perspective targeting low-income countries. Science of the Total Environment. v. 753, 2020.

ISLEK, C.; UNAL, B.T. Copper toxicity in Capsicum annuum: Superoxide dismutase and catalase activities, phenolic and protein amounts of in-vitro-grown plants. Polish Journal of Environmental Studies. v. 24, n. 6, p. 2441-2445, 2015.

KIM, H.K.; IHM, K.S. "Heterogeneous catalytic wet air oxidation of refractory organic pollutants in industrial wastewaters". Journal of Hazardous Materials. v. 186, n. 1, p. 16-34, 2011.

LEONET, A.B; PRADO, E.L; OLIVEIRA, S.V.W.B. Saneamento Básico no Brasil: Considerações Sobre Investimento e Sustentabilidade para Século XXI. Revista de Administração Pública. v. 45, n. 2, 2011.

LI, X.; LI, Y.; XU, D.; QIU, Z.; ZHU, H.; TIAN, H. Effects of solar aeration on purification capacity of floating constructed wetlands with biochar. Environmental Science Technology. 41, n. 7, p. 54-59, 2018.

LI, W.; KHAN, M. A.; YAMAGUCHI, S.; KAMIYA, Y. Effects of heavy metals on seed germination and early seedling growth of Arabidopsis thaliana. Plant Growth Regulation, v. 46, p. 45-50, 2005.

MATAFONOVA, G.; BATOEV, V. Recent advances in application of UV lightemitting diodes for degrading organic pollutants in water through advanced oxidation processes: A review. Water Research. v. 132, p. 177-189, 2018.

MELO, N.M.M.; MORAES, C.M.; OLIVEIRA, D.C.; FREITAS, J.J.R.; DIAS, F.F.S.; OLIVEIRA, C.G.C.; BENACHOUR, M.; BRANDÃO, Y.B. Toxicidade nas Sementes da Lactuca Satica (alface) por Amostras de Efluentes de Esgoto Doméstico Coletadas no Recife-PE com Análise Físico-Química e Microbiológica. Conjecturas, v. 21, n. 2, 2021. https://doi.org/ 10.53660/CONJ-261-117.

MERT, B.K.; YONAR, T.; KILIÇ, M.Y.; KESTIOĞLU, K. Pre-treatment studies on olive oil mill effluent using physicochemical, Fenton and Fenton-like oxidations processes. Journal of Hazardous Materials. v. 174, Issues 1-3, 2010.

METCALF; E. Tratamento de efluentes e recuperação de recursos. 5. ed. Porto Alegre: AMGH, p. 1980, 2016. 
MICHAEL-KORDATOU, I.; KARAOLIA, P.; FATTA-KASSINOS, D. The role of operating parameters and oxidative damage mechanisms of advanced chemical oxidation processes in the combat against antibiotic-resistant bacteria and resistance genes present in urban wastewater. Water Research. v. 129, p. 208-230, 2018.

MICHELAN, D.C.G.S.; SANTOS, W.N.A.; ROSA, T.S.; SANTOS, D.G.; JESUS, R.C.S. Uso do coagulante/floculante emergente à base de moringa no tratamento de água com verificação da composição e toxicidade do lodo produzido: tratamento de água com Moringa e toxicidade do lodo. Engenharia Sanitária e Ambiental, v. 26, n. 05, 2021.

MS. Ministério da Saúde. Portaria. N0 1469 MS. Brasília. 29/12/2000.

MUSHI, V.; SHAO, M. Tailoring of the ongoing water, sanitation and hygiene interventions for prevention and control of COVID-19. Tropical Medicine and Health, v. 48, n. 1, p. 47, 2020.

NIVALA, J.; WALLACE, S.; HEADLEY, T.; KASSA, K.; BRIX, H.; VAN AFFERDEN, M.; MÜLLER, R. Oxygen transfer and consumption in subsurface flow treatment wetlands. Ecological Engineering, v. 61, parte B, p. 544-554, 2013.

PEREIRA, M.S.; MAGALHÃES FILHO, F.J.C.; LIMA, P.M.; TABAK, B.M.; CONSTANTINO, M. Sanitation and water services: Who is the most efficient provider public or private? Evidences for Brazil. Socio-Economic Planning Sciences, 2021. https://doi.org/10.1016/j.seps.2021.101149.

REIS, D.A.; ESPERIDIÃO, F.; JORGE, M.A.; RIBEIRO, L.C.S.; MOTA, T.S.; SANTOS, J.C.N.; SILVA, A.T. Estudo Bibliométrico da Produção Científica Nacional e Internacional no Setor de Saneamento. Revista GEINTEC. v. 7, n. 1, p. 3669-3685, 2017.

REYNALDO, A.M.O; LACERDA, N; JUCÁ, S. Reconfiguração espacial da Região Metropolitana do Recife. Processo de fragmentação e integração. In: Román Caracciolo; Pablo Elinbaum; Biel Horrach Estarellas; Mariana Debat. (Org.). La metrópoles iberoamericana em suspropios términos. 1ªed. Barcelona: RIURB, p. 117-129, 2013.

RIBEIRO, J.C. Avaliação de uma Estação Compacta de Tratamento de Esgoto Sanitário Composta por Reator UASB - Biofiltro Aerado Submerso. 2016. 157 f. Dissertação (Mestrado) - Curso de Pós-graduação em Engenharia Civil e Ambiental, Universidade Estadual Paulista "Júlio de Mesquita Filho", Bauru, 2016.

SANTOS, A.R.; SALES, M.L.; CAMPOLINO, M.L. Sementes de lactuca sativa (alface) como bioindicador da toxicidade da água dos córregos urbanos J.K e Interlagos, região sudeste de sete lagoas, Minas Gerais. Revista Brasileira de Ciências da Vida, v. 5, n. 1, p. 1-14, 2017.

SARAFI, E., TSOUVALTZIS, P., CHATZISSAVVIDIS, C., SIOMOS, A., THERIOS, I. Melatonin and resveratrol reverse the toxic effect of high boron (B) and modulate biochemical parameters in pepper plants (Capsicum annuum L.). Plant Physiology and Biochemistry, v. 112, p. 173-182, 2017. 
SCHIJVEN, J.; TEUNIS, P.; SUYLEN, T.; KETELAARS, H.; HORNSTRA, L.; RUTJES, S. QMRA of adenovirus in drinking water at a drinking water treatment plant using UV and chlorine dioxide disinfection. Water Research. v. 158, p. 34-45, 2019.

SIEBERT, A.P.F.; SILVA, A.C.B.; MORAES, C.M.; BEZERRA, R.S.; SILVA, L.C.M.; OLIVEIRA, D.C.; BENACHOUR, M.; BRANDÃO, Y.B. Utilização da Moringa Oleífera Lam e da Radiação Solar no Tratamento de Água para Consumo Humano. Brazilian Journal of Development. v. 6, n. 11, p. 86102-86129, 2020.

SILVA, J.G; QUEIROZ, S.N. Mobilidade Pendular na Região Metropolitana de Recife (RMR). XVII ENANPUR, São Paulo, 2017.

USEPA, Ecological Effects Test Guidelines: seed germination/root elongation toxicity test, Washington, 1996.

WAGNER, L.F.; WIECHETECH, G.K.; SZÉLIGA, M.R. Evaluation of wastewater treatment plant with anaerobic reactor receiving sludge from water treatment plant Actiflo. Engenharia Sanitaria e Ambiental. v. 24, n. 4, p. 709-717, 2019.

WORLD HEALTH ORGANIZATION (WHO). Guidelines for Drinking-water Quality 4a ed. Genebra: WHO, 2011.

WORLD HEALTH ORGANIZATION (WHO). Water, sanitation, hygiene, and waste management for SARS-CoV-2, the virus that causes COVID-19, 2020. Disponível em: https://www.who.int/publications-detail-redirect/WHO-2019-nCoV-IPC-WASH-2020.4 Acesso em: 24 set. 2020.

YOUNG, B.J.; RIERA, N.I.; BEILY, M.E.; BRES, P.A.; CRESPO, D.C.; RONCO, A.E. Toxicity of the effluent from an anaerobic bioreactor treating cereal residues on Lactuca sativa. Ecotoxicology and Environmental Safety, n. 76, p. 182-186, 2012.

YRUELA I. Cu in plants: acquisition, transport and interactions. Funct Plant Biol. 36, 409, 2009.

ZHANG, L., ZHAO, J., CUI, N., DAI, Y., KONG, L.,WU, J., CHENG, S. Enhancing thewater purification efficiency of a floating treatment wetland using a biofilm carrier. Environmental Science Pollution Research. v. 23, p. 7437-7443, 2016. 